\title{
Alocação de gasto público no município de Marau: uma reflexão crítica sobre o processo de tomada de decisão gerencial e o desenvolvimento econômico
}

\author{
Rodrigo Ferneda* \\ Luiz Fernando Fritz Filho** \\ Denize Grzybouski**** \\ Guilherme de Oliveira*****
}

\begin{abstract}
Resumo
O objetivo deste artigo é discutir os fundamentos teóricos que orientam o processo de tomada de decisão gerencial no nível da administração pública municipal. Para tanto, fazse necessário analisar a natureza dos gastos públicos municipais e identificar aquele que contribuiu positivamente para o desenvolvimento local. A descentralização fiscal e o pacto federativo impressos na Constituição federal de 1988 foram os pilares da democratização do Brasil nos anos 1990, mas as finanças públicas são um problema gerencial para a consolidação da estabilidade macroeconômica e a retomada de investimentos em grande parte dos municípios brasileiros. Os procedimentos metodológicos adotados para realização do estudo empírico foi de estudo de caso, com abordagem quantitativa dos dados coletados em Marau (RS), município que ocupa a primeira posição no índice da Federação das Indústrias do Estado do Rio de janeiro (Firjam) de Desenvolvimento Municipal. Os resultados obtidos indicam aumento da receita líquida, dos investimentos e das despesas correntes, com redução das despesas de capital no período em análise. A composição dos gastos no município de Marau apresenta-se da seguinte forma: gasto social > gasto mínimo > gasto econômico.
\end{abstract}

Palavras-chave: Gastos públicos. Política pública. Gasto público local. Desenvolvimento econômico.

Administrador. Especialista em Economia e Gestão Empresarial (UPF). Endereço: Rua Santos Dumont, 760, Centro, CEP 99150-000, Marau (RS). E-mail: rodrigo ferneda@hotmail.com

** Administrador. Doutor em Desenvolvimento Rural (UFRGS). Endereço: BR 285, Bairro São José, CEP: 99052-900, Passo Fundo (RS).E-mail: fritz@upf.br

*** Administradora. Doutora em Administração (UFLA). Endereço: BR 285 - Km 171 - Campus I, Bairro São José, 99001-970 - Passo Fundo, RS - Brasil. E-mail: gdenize@upf.br.

****** Economista. Mestre em Economia pelo Programa de Pós-Graduação em Economia do Desenvolvimento da PUCRS. Aluno do Doutorado em Economia do Desenvolvimento pela FEA/USP. E-mail: eco.gui@hotmail.com

http://dx.doi.org/10.5335/rtee.v21i44.5360

Submissão: 10/05/2014. Aceite: 02/10/2014. 


\section{Introdução}

As finanças públicas são um problema para a estabilidade macroeconômica e a retomada de investimentos no Brasil. Se, por um lado, o crescimento econômico, o aumento da fiscalização e do emprego formal garantiram a elevação das receitas públicas, quadro dependente da política fiscal dos ciclos econômicos (KLEIN, 2010), de outro modo, a não adoção de medidas de redução do custeio comprometeram o superávit econômico. Dessa forma, o governo brasileiro ficou sem recursos para realizar investimentos (FARAH, 2008), situação considerada como uma ação estratégica que provoca incremento nos índices de crescimento econômico (SIEDENBERG, 2006).

O desenvolvimento é um tema controverso, que pode ser debatido por duas óticas, dos pontos de vista microeconômico e macroeconômico. Pela perspectiva macro, o desenvolvimento é decorrente do crescimento da economia, da geração de inovações e da superação de problemas econômicos e sociais bem como das armadilhas de pobreza (FOLEY; MICHL, 1999). Já pela abordagem micro, o desenvolvimento é essencialmente um estágio de superação das falhas de coordenação, tanto via mercado, vetores de preço ou barganha multilateral, quanto pela presença do Estado na economia.

Para os pesquisadores que não acreditam que a livre iniciativa pode promover resultados eficientes devido à existência de falhas de coordenação micro e estabilidades macro econômicas (BOWLES, 2006), o papel do Estado na economia torna-se preponderante. Nesse sentido, emergem na literatura análises dos impactos na sociedade da atuação estatal, como a provisão de bens públicos, a distribuição de renda aos agentes econômicos, a democracia, e, sobretudo, as avaliações de estabilidade e efetividade dos gastos públicos (federais e regionais) para a promoção do desenvolvimento (SAMUELSON, 1955; MUSGRAVE, R. A.; MUSGRAVE, P. B., 1980).

O objetivo deste artigo é discutir os fundamentos teóricos que orientam o processo de tomada de decisão gerencial no nível da administração pública municipal, o que se faz a partir da análise da natureza dos gastos públicos municipais e da identificação daquele que contribuiu positivamente para o desenvolvimento local. Para dar conta desse propósito, optou-se por realizar um estudo no município de Marau, no interior do estado do Rio Grande do Sul, tomando como recorte analítico o período de 2003 a 2011, o que se configura como um estudo de caso.

De acordo com a nova geografia econômica (COELHO, 2013), não se pode argumentar em favor de sólidas estruturas sobre a política de subsídios e isenções fiscais para obter eficiência e utilizá-la como mecanismo de descentralização regional. 
Há incertezas sobre a existência de fatores aglomerativos que podem compensar em larga medida os incentivos fiscais. A política fiscal tem mais eficácia quando o objetivo é obter melhorias na distribuição de renda, tanto pela taxação às rendas mais altas como pelo aumento dos gastos do governo com a destinação de setores menos favorecidos (VASCONCELOS; GARCIA, 2008).

O estudo justifica-se devido à pouca atenção que os gastos públicos têm recebido nos estudos sobre finanças públicas no Brasil, que conferem maior ênfase às práticas políticas, e não à realidade econômica em um contexto local. A Constituição federal de 1988 (CF/1988) provocou impacto negativo sobre as finanças públicas, definindo diretrizes para a descentralização fiscal, que ligadas à implantação do Plano Real, em 1994, deu início a uma nova fase na política fiscal do Brasil. O controle da inflação tornou mais visível os problemas de alocação de recursos nas contas públicas, uma vez que a inflação constituía-se fonte de financiamento do setor público, reduzindo as despesas públicas a termos reais.

Esse novo contexto de mudanças trouxe aos governos municipais uma série de desafios na tentativa de melhorar seu desempenho. A defasagem na sistemática dos processos e os cadastros não atualizados geraram impactos na arrecadação, deficiência na gestão, em tecnologias, e outras situações que provam a ineficiência da máquina pública em questão de atendimento e solução de problemas dos municípios.

Tais conteúdos são apresentados neste artigo em quatro partes. Inicia-se com a revisão teórica sobre o tema política fiscal e seus impactos no desenvolvimento econômico, o esforço fiscal e o comportamento do produto interno bruto (PIB) no Município de Marau (RS). Na segunda parte, apresenta-se a metodologia utilizada para o estudo empírico e, por fim, apresentam-se os resultados e as considerações finais do estudo.

\section{Referencial teórico}

\subsection{Política fiscal e desenvolvimento econômico: entre as falhas de coordenação e a resposta institucional}

Desde os primórdios da Economia enquanto ciência, os economistas têm se perguntado por que algumas nações crescem mais do que outras? Adam Smith, em 1776, alertou que os diferentes comportamentos de crescimento eram explicados pelas diferenças de produtividade do trabalho entre as regiões. Ele sugeriu, então, a divisão do trabalho para que os países garantissem maiores níveis de produto 
per capita. A tradição smithiana de olhar para o crescimento foi seguida por David Ricardo, Thomas Malthus e seu principal crítico, Karl Marx.

Schumpeter (1982) foi o primeiro economista a "contestar" essa visão estritamente focada no crescimento econômico no início do século XX, sendo também o primeiro a cunhar o termo desenvolvimento econômico. Para o autor, falar sobre crescimento era interpretar a economia por meio do modelo de equilíbrio geral walrasiano, que o próprio autor representava no seu fluxo circular da renda. No entanto, a análise deveria ser realizada contemplando a figura do empresário inovador, que incorporava ideias ao processo produtivo e criava novos produtos, e assim expandiria ao sistema econômico.

A literatura do desenvolvimento econômico, entretanto, evoluiu muito ao longo do século XX, passando pelos modelos de Harrod-Domar (1939), Rosensteim-Rodan (1943), Prebrisch (1949), Myrdal (1954), Solow (1969), Romer (1986), dentre tantos outros economistas, todos focados em uma abordagem macroeconômica do problema do desenvolvimento. ${ }^{1}$ De outro modo, a economia neoclássica também contempla a abordagem do desenvolvimento pela ótica microeconômica. Nesses termos, o problema desenvolvimentista pode ser encarado como a tarefa de lidar com as falhas de coordenação do sistema capitalista.

Falhas de coordenação são problemas de ausência ou ineficiência na alocação de bens e serviços entre indivíduos (MAS-COLELL; WHINSTON; GREEN, 1995). Elas surgem quando os agentes, agindo por seu próprio interesse - maximizando suas utilidades - não conseguem atingir o nível de ótimo social, ou seja, o ponto em que nenhum indivíduo consegue melhorar sua situação sem piorar a de outro. A taxonomia das falhas de coordenação incorpora desde o problema do common pool, às externalidades positivas ou negativas, à provisão de bens públicos até os problemas de informação assimétrica (BOWLES, 2006).

$\mathrm{Na}$ tradição microeconômica, o problema do desenvolvimento resume-se a minimizar a influência das falhas de coordenação no sistema econômico. Duas correntes de solução são propostas: (a) descentralizadas pelos próprios agentes envolvidos, bastando criar condições para que a troca aconteça; (b) centralizadas, soluções que necessitam do Estado.

Na primeira corrente, dois grupos concorrem: as soluções de mercado fundamentadas no paradigma Arrow-Debreu (1954), ${ }^{2}$ em que bastaria criar mercados privados em que eles não existam para que os agentes promovam a troca ótima; e o processo de barganha multilateral entre os agentes, essencialmente fundamentais no Teorema de Coase (1988). Nesse último, cresce a importância da existência de instituições eficientes que minimizam os custos de transação, criando condições 
para que a barganha entre os agentes possa ocorrer, são condições sine qua non para o desenvolvimento econômico de nações, regiões ou municípios (NORTH, 1990; ACEMOGLU; JOHNSON; ROBINSON, 2001, 2002).

Para a segunda corrente, o problema do desenvolvimento só pode ser resolvido com a presença do Estado, corrigindo as falhas de coordenação. Nesse caso, teorias de provisão ótima de bens públicos e abordagens macroeconômicas da política fiscal são preponderantes, tanto no ambiente neoclássico como no heterodoxo (BOWLES, 2006). Nesse contexto, Samuelson (1955), Tiebout (1956) e Oates (1977) são alguns dos autores clássicos e importantes para elaboração e disseminação das teorias em finanças públicas.

A teoria que se desenvolveu em finanças públicas é em grande parte de tradição neoclássica, focando, portanto, nas questões de eficiência da atuação estatal, baseadas na economia do bem-estar e na otimalidade do equilíbrio geral via Arrow-Drebeu. Nesse sentido, a atuação estatal deve ser tal que não altere os preços relativos dos bens da economia, garantindo que os agentes maximizem suas escolhas por meio de alocações ótimas ${ }^{3}$ (MAS-COLELL; WHINSTON; GREEN, 1995). Portanto, compreender o papel do Estado na economia torna-se fundamental.

Nos estados organizados federativamente, como é o caso do Brasil, as unidades federadas e os diversos municípios dividem a responsabilidade pelas funções alocativa, distributiva e estabilizadora da economia. A grande questão em termos de administração fiscal é definir as competências que serão atribuídas a cada nível de governo, ou seja, a permissão do grau de autonomia para que se alcance o grau eficiente de Pareto na intervenção.

A função alocativa deve ser compartilhada entre os diferentes níveis de governo, segundo seu grau de correspondência entre as preferências, a tributação dos agentes da economia e a provisão de bens públicos. Nesse ponto, é justamente a multiplicidade de preferências dos indivíduos do sistema econômico que explica a divisão federativa no Brasil, um desenho que em tese permite a maximização do bem-estar dos agentes residentes em cada unidade governamental, em uma perspectiva neoclássica (MUSGRAVE, R. A.; MUSGRAVE, P. B., 1980).

Oates (1977) afirma que o modelo ideal prevê que a organização descentralizada em vários entes governamentais seja a mais eficiente, maximizando o bem-estar dos agentes do sistema econômico. Nesse quadro, a forma federativa que maximiza o bem-estar é aquela em que a provisão dos bens públicos é realizada, tomando-se por base que o indivíduo contribui de acordo com o seu bem-estar, que foi obtido pela cesta de bens ofertados. Nesse contexto, o governo central deve se responsabilizar pela provisão de bens e serviços cujo consumo seja uniforme, já os 
governos locais alocariam recursos e resolveriam falhas de coordenação de acordo com as preferências regionais.

No que diz respeito às políticas distributivas, também seriam competência de ambas as esferas governamentais, e deveriam obedecer às características das distribuições do tipo lump sum, ou seja, as políticas de redistribuição não poderiam afetar os preços relativos da economia. Por exemplo, uma política de racionamento (de água, de carros, etc.) que afeta diretamente a preferência dos agentes por mecanismos extramercado não é ótima, porque afeta a escolha individual, o que afetaria, por sua vez, o preço relativo dos bens e serviços. A política redistributiva ótima, nesse caso, seria como um imposto, que não afeta o preço relativo dos produtos: se um indivíduo estiver disposto a usar o bem racionado, pagaria uma taxa adicional e a característica de privacidade na escolha de suas preferências seria preservada (SAMUELSON, 1955).

Com relação ao último papel do Estado na economia, a função estabilizadora é aquela que defende a intervenção estatal na economia por intermédio de uma política anticíclica, no seu sentido keynesiano mais clássico. Os mecanismos de atuação seriam gastos públicos em investimentos e a manipulação da taxa de juros, visando a estimular a economia em tempos de baixa do ciclo de negócios, e o afastamento durante os períodos de ascensão, alcançando superávits para os próximos momentos de crise (MUSGRAVE, R. A.; MUSGRAVE, P. B., 1980). Assim, os mecanismos que financiam a atuação do Estado nas suas diferentes esferas, enquanto agente econômico, são os tributos pagos pelas empresas e consumidores do sistema, e o recurso que é empregado para captação ótima dos governos é a chamada política tributária.

\subsection{Política tributária e alocação de gastos públicos}

A política fiscal é composta por duas práticas: tributação e gastos do governo. A tributação é utilizada pelo governo com o objetivo de auferir receitas necessárias para a realização de seus empreendimentos na economia, por meio da cobrança de uma taxa sobre a renda ou sobre a quantidade de produtos vendidos (RIANI, 2002). Os estudos das finanças públicas realizados por Riani apontam que:

Os gastos públicos são apresentados e classificados de acordo com sua finalidade, sua natureza e sua função, os quais têm o objetivo de destacar seus desmembramentos segundo as funções e os programas a serem executados pelo governo. Essa classificação é importante para a implantação do orçamento-programa, na qual o objetivo é aumentar a eficiência e a eficácia na programação dos gastos do governo (2002, p. 80). 
Para Oates (1977), o sistema federalista proporciona maior separação das políticas tributária e monetária, contribuindo para que estados e municípios apresentem restrições orçamentárias rígidas com condição de assegurar melhor eficiência alocativa dos gastos públicos.

O governo federal utiliza a política fiscal associada a outras políticas para equilibrar a economia nacional, pois a administração das finanças públicas no Brasil se estabelece em três níveis de governo: a União, os estados e os municípios. $\mathrm{O}$ Código Tributário Nacional (CTN) regulamentou as competências específicas de cobrança dos tributos sobre as atividades produtivas da sociedade e definiu tributos como sendo impostos, taxas, contribuições de melhoria, empréstimos compulsórios e contribuições parafiscais. Dessa forma, políticas fiscais e monetárias do governo federal prevalecem sobre as finanças públicas regionais, obrigando os governos estaduais e municipais a adotarem políticas fiscais em consonância com as políticas nacionais (POHLMANN; IUDÍCIBUS, 2006).

Os gastos do governo são os investimentos gerados, pelo menos em favor da economia, e objetivam uma oferta de bens e serviços indispensáveis à sociedade, que muitas vezes não são oferecidos pelo setor privado. Os investimentos são distribuídos em cotas destinadas à habitação, ao saneamento básico, à saúde, à educação, à cultura e à infraestrutura. Faz-se isso por meio de recursos que, destinados de forma eficiente e justa, promovem benefícios locais: aumento da qualidade de vida, desenvolvimento de novas tecnologias, infraestrutura para criação e atração de novos investidores, aumento de empregabilidade, entre outros citados por Vasconcelos e Garcia (2008), como fatores que influenciam o nível de produto per capita de uma economia.

Para Vasconcelos e Garcia (2008), os gastos de transferências e subsídios são considerados nas contas nacionais como transferências, donativos, pensões e subsídios, e não são computados como parte da renda nacional, pois representam apenas uma transferência financeira do setor público ao setor privado, não havendo qualquer aumento da produção corrente. As aposentadorias e bolsas de estudo não são fatores de produção do período corrente. A Figura 1 apresenta as transferências voluntárias da União aos municípios brasileiros em valores originais no período 1997-2010. 
Figura 1 - Transferências voluntárias da União aos municípios brasileiros 1997-2010, em valores originais $(\mathrm{R} \$ \mathrm{mil})$

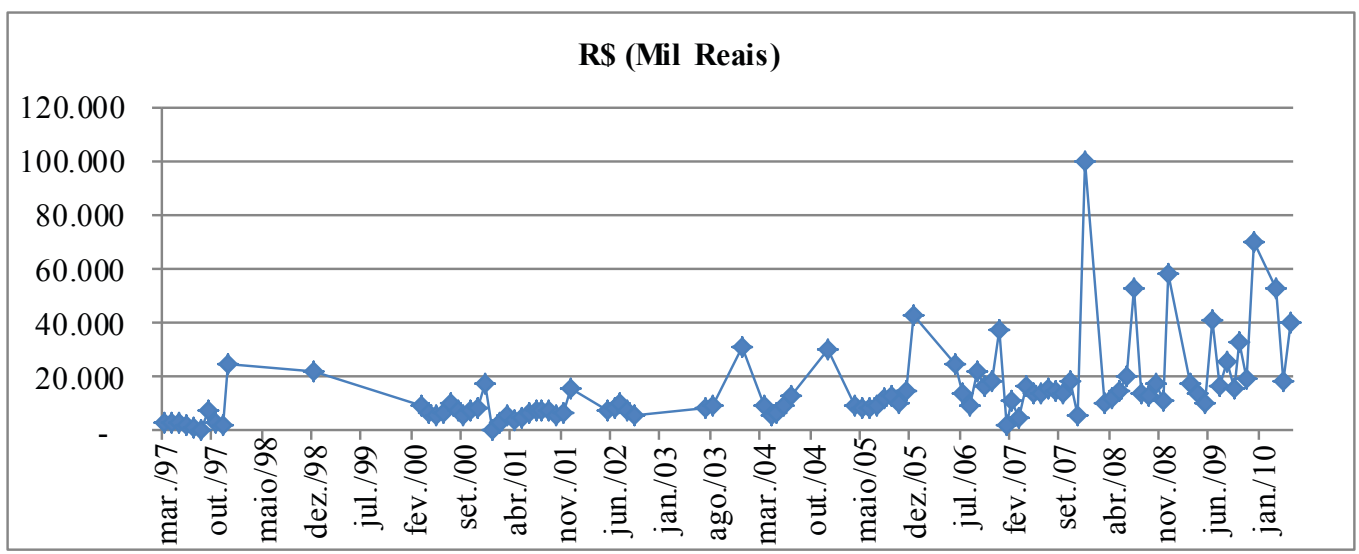

Fonte: Tesouro Nacional (2010).

Nota: não inclui restos a pagar.

De acordo com a Figura 1, no período que compreende de 1997 até meados de 2008, nota-se que as transferências permaneceram estáveis, porém, de 2008 até os momentos atuais, vivenciou-se a crise econômica mundial, que elevou as transferências, na tentativa de estabilizar as expectativas e a incerteza dos agentes quanto ao futuro, proporcionando condições para que haja uma retomada do estado de confiança, por meio da utilização fiscal caracterizada pela redução de impostos, expansão dos gastos públicos e pela atuação do Estado na coordenação, ordenação e regulamentação do sistema econômico.

No que compreende a natureza dos gastos, segundo classificação elaborada por Rezende (1997), há o gasto mínimo (GM), o gasto social (GS) e o gasto econômico (GE). O GM corresponde às parcelas de gastos governamentais em políticas públicas considerados como domínio exclusivo do governo. Essa classificação envolve a provisão de bens e serviços que se enquadram na categoria de bens públicos puros, que não podem ser provisionados por mecanismos de mercado, representando campos de domínio exclusivo do governo. O gasto social (GS), por sua vez, corresponde à parcela do gasto em políticas públicas destinada à provisão de bens $\mathrm{e}$ serviços meritórios ou do tipo quase-públicos. Tais bens, devido ao grau de exclusão e divisibilidade relativa ao consumo, não permitem que o governo assuma posição monopolista mediante adoção de mecanismo de mercado para a alocação de tais recursos. E, o gasto econômico $(\mathrm{GE})$ corresponde à parcela do gasto que diz respeito 
a atividades econômicas nas quais o governo não teria necessidade de se envolver. Assim, na prática, o governo desempenha as atividades devido à necessidade da regulação de mercados ou, em casos de intervenção direta, desempenhando atividades empresariais.

A análise da natureza desses gastos possibilita compreender a dinâmica e a evolução das preferências alocativas dos governos locais por políticas públicas em um dado período de tempo bem como analisar a evolução das preferências alocativas e identificar as tendências na composição de tais preferências.

\subsection{Esforço fiscal}

A relação entre gastos públicos e desenvolvimento econômico tem importante implicação de política econômica. Desde 2008, no decorrer da crise financeira internacional, o governo fez um esforço fiscal para manutenção da retomada do crescimento (política anticíclica) baseado em medidas voltadas a recuperar a economia e reaquecer o mercado, gerando superávit primário, embora também gastando bastante.

No período de crise, em especial no ano 2011, por exemplo, o governo brasileiro adotou um conjunto de medidas, como redução de tributos (IOF das operações realizadas por pessoas físicas; IPI incidente sobre eletrodomésticos), cujo objetivo foi estimular a economia e manter a atividade aquecida com vistas a manter a produção e os empregos (PORTAL BRASIL, 2011). Como medidas econômicas adotadas em relação à crise, destaca-se a redução da alíquota do Imposto sobre Operações de Crédito, Câmbio e Seguros (IOF) sobre as operações de crédito com pessoas físicas, a criação de alíquotas adicionais intermediárias para o Imposto de Renda, o reajuste dos benefícios previdenciários, a ampliação de gastos com os programas sociais, o aumento de recursos para o Banco Nacional de Desenvolvimento Econômico e Social (BNDES) e o crédito rural.

Apesar do esforço fiscal que o governo federal realiza desde 2008 para atingir o superávit primário, o Brasil ainda tem baixo crescimento (NEDUZIAK, 2013), o que provoca baixos investimentos públicos, elevada dívida pública, despesa corrente e gastos previdenciários, ineficiência na política de gestão de pessoas. Esses fatores são apontados como origem da vulnerabilidade no longo prazo e que inviabilizam o ajuste fiscal (GADELHA; DIVINO, 2008; FARAH, 2008; KLEIN, 2010; NEDUZIAK, 2013).

A competição tributária entre governos do mesmo nível e de diferentes níveis em uma federação gera externalidades sobre as receitas tributárias de cada ente 
federado (FARAH, 2008; KLEIN, 2010). Assim, se um Estado, que cria empregos e renda em seu território, reduz as alíquotas dos tributos de sua competência, gera impactos sobre as finanças públicas dos demais estados. A regra vale também entre municípios, caso um município resolva alterar as alíquotas de seus impostos.

A adoção de regras fiscais tem sua importância para os estados, pois é de sua competência a arrecadação do imposto indireto que mais se aproxima de um imposto sobre valor adicionado no Brasil, consequentemente do que deve apresentar mais correlação com o PIB (VASCONCELOS; GARCIA, 2008). As variações da base tributária dos estados guardam estreita relação com o PIB, em especial se comparadas às bases dos impostos federais e municipais. $\mathrm{O}$ motivo para construir um indicador de referência que suponha razão constante entre arrecadação e PIB reside no fato de não se ter desejado mudanças na política tributária ao longo do período analisado; por trás do desenho do modelo adotado há indicação de regra fiscal a ser seguida.

Convém ressaltar a importância do valor adicionado bruto (VAB), que é uma medida da riqueza social gerada em uma região em determinado período, ou seja, o valor de todas as mercadorias que entram na produção de outras mercadorias é descontado do valor total das mercadorias produzidas (FISCHER; DORNBUSCH, 1991).

Para Pohlmann e Iudícibus (2006), a tributação ótima é uma abordagem para a análise tributária baseada em ferramentas padrões da economia do bem-estar, aplicada em um contexto quando a melhor alocação de recursos e distribuição de renda não pode ser obtida. Para os autores, a abordagem usual da tributação ótima é baseada em diferentes metodologias, entre os quais se destaca a governamental, pois exige-se um montante especificado de receita, limitado aos tipos de instrumentos tributários disponibilizados para isso. Suas decisões devem ser consistentes com a otimização dos recursos e sua escolha orientada pela maximização da função de bem-estar social.

O rateio da arrecadação de impostos entre os entes federados representa um mecanismo fundamental para reduzir as desigualdades regionais, objetivando o equilíbrio socioeconômico entre estados e municípios. Moura Neto e Palombo (2006) afirmam que com a CF/1988 descentralizou-se grande parte dos recursos da União para estados e municípios, aumentando a proporção dos impostos de renda e sobre produtos industrializados destinados ao Fundo de Participação dos Municípios (FPM).

Para os municípios, as principais transferências federais são os fundos de Participação dos Municípios, compostos por 22,50\% da arrecadação de Imposto de 
Renda Pessoa Jurídica (IRPJ) e IPI, 70\% da arrecadação do IOF Ouro, 50\% dos recursos arrecadados do Imposto sobre a Propriedade Territorial Rural (ITR) e 100\% dos recursos retidos na fonte. Do Estado advém 25\% do Imposto sobre Circulação de Mercadorias e Serviços (ICMS) arrecadado no município, do Fundo Estadual de Produtos Industrializados, e parcela equivalente a 50\% do Imposto sobre a Propriedade de Veículos Automotores (IPVA) recolhido na localidade (AFONSO et al., 1998). Assim, o FPM representa a principal fonte de financiamento para grande parte das prefeituras.

Na visão de Moura Neto e Palombo (2006), as regras de repartição do FPM incentivaram a proliferação de novas unidades municipais, na maioria dos casos muito pequenas e sem a menor condição de se sustentarem sem os repasses do governo federal. As transferências de fato equalizam a capacidade de gastos dos municípios brasileiros devido à heterogeneidade de tamanho e renda das unidades locais. Para os autores, não é de acordo com o princípio da equidade regional e o inventivo de criação de novas unidades sem base econômica própria, sustentadas exclusivamente por recursos advindos de outras localidades mais ricas. Isso ocorre porque a maior parte dos recursos não está vinculada a nenhum tipo de gasto público, permitindo à burocracia municipal alocá-los de forma livre, sem haver qualquer tipo de mecanismo de acompanhamento e avaliação desses gastos (KLEIN, 2010).

\section{Procedimentos metodológicos}

Trata-se de uma pesquisa descritiva feita em contas e gastos públicos realizados pela administração pública do município de Marau, o que se caracteriza como um estudo de caso, com abordagem quantitativa e uso da estatística descritiva simples para o tratamento dos dados.

O objeto de estudo são as contas do município de Marau, no estado do Rio Grande do Sul, localizado no planalto sul-rio-grandense, emancipado em 1954, com origem nos municípios de Passo Fundo e Guaporé. Hoje, o município tem área de $649,3 \mathrm{~km}^{2}$, com população de 37.443 habitantes, densidade demográfica de $56,7 \mathrm{ha} /$ $\mathrm{km}^{2}$, taxa de analfabetismo de $3,03 \%$, mortalidade infantil de $8,05 \%$ por mil nascidos vivos, e expectativa de vida de 74,64 anos (FEE, 2013). É conhecido como Capital Regional da Indústria, pois possui 285 estabelecimentos industriais que empregam 54\% da mão de obra local. O setor de serviços, com 367 empresas, corresponde a $24,23 \%$ da mão de obra local, enquanto o setor da agropecuária, que conta com 62 empresas, é responsável por 2,04\% dos empregos gerados, e o setor do comércio 
é responsável por 13,70\%, com 465 empresas (RAIS, 2010). A economia de Marau tem sua dinâmica ligada às indústrias metalomecânicas e de transformação, e como atividades secundárias apresentam-se o comércio varejista, os serviços diversos e a agropecuária, que ocupam a mão de obra local. A renda per capita do município é de $\mathrm{R} \$$ 40.793,00 (FEE, 2013).

A escolha deste objeto de estudo deu-se pelo fato de que o município está na primeira posição, entre os 497 municípios do Rio Grande do Sul, do índice Firjam de Desenvolvimento Municipal (IFDM), um dos mais conceituados indicativos do país em assuntos direcionados ao desenvolvimento dos municípios, levando em conta índices de saúde, educação e geração de emprego.

Os dados primários relativos aos anos de 2003 a 2011 foram obtidos com as secretarias municipais da Fazenda, da Indústria e Comércio, da Agricultura, da Saúde, dos Transportes, do Desenvolvimento Econômico, da Assistência Social e da Habitação e Turismo, em setembro de 2012. Para homogeneizar os dados, os valores foram deflacionados pelo Índice Geral de Preços-disponibilidade interna (IGP-DI) (base = 1994) com base no Ipea (2013). Os dados secundários foram obtidos em diferentes bases de dados, como FEE, Instituto Brasileiro de Geografia e Estatística (IBGE) e RAIS. Todos os dados foram tabulados em planilhas eletrônicas, utilizando-se o software Microsoft Excel.

O procedimento de análise dos dados sobre os gastos mínimo, social e econômico seguiu a metodologia proposta por Rezende (1997), com a composição funcional dos gastos públicos e a natureza alocativa do governo. Ver na Tabela 1.

Tabela 1 - Gastos públicos e a natureza alocativa do governo

\begin{tabular}{l|l|l}
\hline \multicolumn{1}{c|}{ Gasto mínimo (GM) } & \multicolumn{1}{|c|}{ Gasto social (GS) } & \multicolumn{1}{c}{ Gasto econômico (GE) } \\
\hline Bens públicos puros & Bens semipúblicos & Bens privados \\
Legislativo & Educação e cultura & Agricultura \\
Judiciário & Saúde e saneamento & Comunicação \\
Administração e planejamento & Assistência e previdência & Desenvolvimento regional \\
Defesa e segurança & Habitação e urbanismo & Energias e recursos minerais \\
& & Indústria, comércio e serviços \\
& & Relações exteriores \\
& & Trabalho Transporte \\
\hline
\end{tabular}

Fonte: Rezende (1997). 
A base dos dados é uma série histórica das preferências alocativas dos governos locais, visto que tais categorias dizem respeito ao fim último da ação do governo, não sendo consideradas as funções de natureza intermediária.

\section{Apresentação e discussão dos resultados}

\section{$4.1 \mathrm{O}$ caso do município de Marau}

A série histórica da Tabela 2 apresenta o comportamento do PIB e do VAB do município, em mil reais, de 2003 a 2010. A mesma regra foi adotada para VAB nos três setores da economia e em seu total.

Tabela 2 - Produto interno bruto, per capita e composição setorial do VAB, em mil reais

\begin{tabular}{|c|c|c|c|c|c|c|c|c|c|c|}
\hline \multirow{2}{*}{ Anos } & \multirow{2}{*}{$\begin{array}{c}\text { PIB Total } \\
\text { (Mil R\$) }\end{array}$} & \multirow{2}{*}{\begin{tabular}{|l} 
População \\
(Pessoas)
\end{tabular}} & \multirow{2}{*}{$\frac{\text { PIBpc }}{(\mathrm{R} \$)}$} & \multirow{2}{*}{$\frac{\text { VAB }}{(\text { Mil } R \$)}$} & \multicolumn{2}{|c|}{ VAB Industrial } & \multicolumn{2}{|c|}{ VAB Serviços } & \multicolumn{2}{|c|}{ VAB Agropecuária } \\
\hline & & & & & (Mil & (\%) & \$) & (\%) & (Mil R\$) & (\%) \\
\hline 03 & 4 & & 26 & 2 & & & & & & 7 \\
\hline 04 & 23 & 28 & $7.369,58$ & 210.0 & $122.887,45$ & 58,50 & $69.058,11$ & 32,87 & 18. & 8,63 \\
\hline 05 & 250. & 48 & $7.719,27$ & $225.099,30$ & $132.400,03$ & 58,82 & $82.364,24$ & 36,59 & 10.3 & 4,59 \\
\hline 006 & $4.361,05$ & 73 & $7.344,12$ & 220. & 118 & 53,50 & 84.6 & 38,36 & 17. & 8 \\
\hline 2007 & 253. & 57 & $7.436,10$ & $230.336,20$ & 114 & 49,59 & 4,53 & 40,23 & 23. & 10,18 \\
\hline 2008 & $238.494,66$ & 791 & $6.855,07$ & 216.2 & $101.486,22$ & 46,93 & $90.668,44$ & 41,92 & 24 & 11,15 \\
\hline 2009 & $280.436,38$ & 35.571 & $7.883,85$ & $255.865,37$ & $135.124,17$ & 52,81 & $97.917,15$ & 38,27 & $22.824,05$ & 8,92 \\
\hline 2010 & $282.256,42$ & 36.364 & $7.761,97$ & $256.254,72$ & $127.852,89$ & 49,89 & $105.002,98$ & 40,98 & $23.398,85$ & 9,13 \\
\hline 2011 & $n / d$ & $n / d$ & $\mathrm{n} / \mathrm{d}$ & $\mathrm{n} / \mathrm{d}$ & $n / d$ & & $n / d$ & & $n / d$ & \\
\hline
\end{tabular}

Fonte: elaboração dos autores com base em dados da FEE (2013).

Em 2003, a indústria representava 54,26\% do VAB, em razão do crescimento da indústria alimentícia, que já desenvolvia atividades no setor de carnes e óleos no município; os serviços representavam $32,97 \%$ e a agropecuária representava $12,77 \%$ do VAB. Em 2010, últimos dados disponíveis no momento da pesquisa, a indústria já havia perdido $4,37 \%$ de representatividade do $\operatorname{VAB}(49,89 \%)$, enquanto que o setor de serviços, que inclui a prestação de serviços, o comércio e a administração pública, cresceu 8,01\%, passando a representar 40,98\% do VAB total. A agropecuária, por sua vez, reduziu $3,64 \%$ de sua participação, representando apenas 9,13\% do VAB total. 
No novo cenário produtivo, os agricultores voltam-se para a diversificação de produtos, e na pecuária ganham destaque as atividades produtivas da avicultura e da pecuária de leite, para atender à demanda das indústrias de alimentos instaladas no município. Devido à indústria ser a principal atividade da economia, outros setores da atividade produtiva também se desenvolvem, atraídos pela mão de obra local e pela oferta de empregos diretos e indiretos, contribuindo para o investimento e o consumo interno no município. Observe os dados na Tabela 3.

Tabela 3 - Principais impostos arrecadados no município de Marau, em mil reais

\begin{tabular}{l|r|r|r|c|c|c|c}
\hline \multirow{2}{*}{ ANO } & \multicolumn{3}{|c|}{ Tributos municipais } & \multicolumn{2}{c|}{ Tributos estaduais } & \multicolumn{2}{c}{ Tributos federais } \\
\cline { 2 - 8 } & \multicolumn{1}{c|}{ IPTU } & \multicolumn{1}{c|}{ ISSQN } & \multicolumn{1}{c|}{ ITIBI } & ICMS & IPVA & \multicolumn{1}{c}{ IPI } & \multicolumn{1}{c}{ IRPJ } \\
\hline 2003 & $474.736,32$ & $229.961,07$ & $144.562,06$ & $6.065 .675,57$ & $740.336,16$ & $542.284,16$ & $1.962 .193,76$ \\
2004 & $427.796,01$ & $292.073,38$ & $141.463,17$ & $5.284 .844,74$ & $712.174,21$ & $558.851,80$ & $2.211 .434,29$ \\
2005 & $449.510,10$ & $411.665,21$ & $178.862,91$ & $2.181 .633,74$ & $790.893,84$ & $343.154,39$ & $1.740 .743,74$ \\
2006 & $449.384,80$ & $425.474,57$ & $190.376,96$ & $2.066 .604,42$ & $920.733,41$ & $402.185,93$ & $1.270 .217,08$ \\
2007 & $478.164,94$ & $438.416,61$ & $222.492,42$ & $3.861 .167,54$ & $960.745,31$ & $454.497,94$ & $2.142 .311,57$ \\
2008 & $585.989,62$ & $529.342,47$ & $324.616,51$ & $4.538 .959,65$ & $1.106 .237,90$ & $571.732,58$ & $1.460 .407,78$ \\
2009 & $560.484,66$ & $610.132,90$ & $291.300,97$ & $8.772 .904,97$ & $1.714 .683,08$ & $359.588,06$ & $1.971 .906,06$ \\
2010 & $619.625,35$ & $662.769,03$ & $290.884,08$ & $10.342 .634,01$ & $1.513 .197,02$ & $263.557,40$ & $2.738 .551,33$ \\
2011 & $n / d$ & $n / d$ & $n / d$ & $n / d$ & $n / d$ & $n / d$ & $n / d$ \\
\hline
\end{tabular}

Fonte: Núcleo de Contabilidade Social - FEE (2013).

Nas últimas décadas, o parque industrial de Marau ganhou destaque nos setores de alimentos, couro, metalomecânica e equipamentos para avicultura e suinocultura, destacando-se o ICMS, o IPI e o IRPJ. O Imposto sobre Serviços de qualquer Natureza (ISSQN) é decorrente das empresas de prestação de serviços e profissionais liberais. Contudo, o Imposto Predial e Territorial Urbano (IPTU) e o Imposto sobre a Transmissão de Bens Imóveis (ITBI $)^{4}$ ganharam destaque devido ao crescimento da cidade, ao surgimento de novos bairros, à elevada oferta de moradia para migrantes.

A Tabela 4 apresenta as principais transferências destinadas ao município de Marau, em mil reais, no período de 2003 a 2011. 
Tabela 4 - Principais transferências realizadas a Marau no período 2003-2011, em mil reais

\begin{tabular}{c|c|c|r|r|r|r|r}
\hline Ano & ICMS & IPVA & FPM & ITR & Lei Kandir & FUNDEB & $\begin{array}{c}\text { Outras } \\
\text { transferências }\end{array}$ \\
\hline 2003 & $4.052 .401,75$ & $324.648,24$ & $1.447 .452,57$ & - & - & $787.883,49$ & $795.550,12$ \\
2004 & $3.734 .394,34$ & $363.421,01$ & $1.434 .994,18$ & - & - & $754.974,46$ & $961.020,75$ \\
2005 & $4.229 .743,69$ & $411.739,23$ & $2.020 .698,02$ & - & - & $889.161,59$ & $1.037 .990,54$ \\
2006 & $4.333 .317,71$ & $446.098,69$ & $2.167 .203,69$ & - & - & $931.442,42$ & $1.015 .141,09$ \\
2007 & $4.064 .635,85$ & $476.280,89$ & $2.361 .845,59$ & - & $-1.104 .415,82$ & $1.095 .710,96$ \\
2008 & $4.876 .294,07$ & $580.528,24$ & $2.753 .573,81$ & - & $-1.620 .515,14$ & $1.161 .386,97$ \\
2009 & $5.114 .043,37$ & $830.798,04$ & $2.656 .720,89$ & $11.979,29$ & $177.520,09$ & $1.914 .445,93$ & $1.249 .498,39$ \\
2010 & $2.564 .414,90$ & $751.455,37$ & $2.564 .414,90$ & $11.494,18$ & $195.392,53$ & $2.196 .352,27$ & $1.088 .313,29$ \\
2011 & $6.042 .042,25$ & $803.713,27$ & $3.027 .177,44$ & $12.769,19$ & $208.408,97$ & $2.397 .177,11$ & $1.193 .836,46$ \\
\hline
\end{tabular}

Fonte: Prefeitura Municipal de Marau (2012).

As principais ações para aumentar a arrecadação podem ser organizadas em três grupos: o aumento da fiscalização, o incentivo à concorrência do fato gerador do tributo e a redução da inadimplência. Em relação aos impostos estaduais, as prefeituras não têm poder de reduzir a inadimplência, mas podem ajudar o Estado na fiscalização do ICMS, estimulando a realização de atividades comerciais ou licenciamento de veículos no município.

De fato, o município de Marau, de 2003 a 2009, apresentou significativas modificações no cenário econômico, como o aumento da população, a construção de novos condomínios residenciais e edifícios, a instalação do parque industrial - com 21 micro e pequenas empresas e 24 empresas em fase de instalação -, o estabelecimento da Faculdade de Educação para qualificação da mão de obra, a melhoria da infraestrutura urbana, a criação de incentivos a eventos e atividades culturais, a implantação de novas práticas na gestão da saúde, com adoção da Estratégia Saúde da Família, a formação de quadro funcional qualificado, a realização de campanhas de prevenção, o atendimento à saúde 24 horas, entre outros projetos em desenvolvimento.

No cenário da educação, houve a qualificação do quadro funcional, a reforma e a melhoria de escolas de ensino fundamental e educação infantil, a informatização das escolas, as parcerias com instituições para portadores de necessidades especiais e o transporte escolar gratuito. A Secretaria de Educação juntamente com a 
Secretaria de Assistência Social controla a frequência escolar dos alunos de baixa renda para que eles possam ter acesso ao benefício do Bolsa Família. As secretarias oferecem oficinas de aprendizagem e qualificação para crianças, adolescentes e suas famílias, grupos de encontros de apoio para a prevenção, tratamento e diagnóstico das famílias que mais carecem desse benefício. Tais atividades desenvolvidas pelas secretarias de Educação e de Assistência Social alteram a dinâmica de alguns setores produtivos. O desenvolvimento dos cidadãos de baixa renda, por meio do ensino formal, das oficinas e grupos de apoio, gera demandas específicas ao setor público, cujo impacto é percebido nos setores da construção civil, do comércio e da prestação de serviços específicos, como educação, saúde, habitação, assistência social.

Na Figura 2, observa-se que, em 2003, a receita foi de $\mathrm{R} \$ 23,90$ milhões e, em 2011, passou a ser de $\mathrm{R} \$ 68,23$ milhões, o que representa um incremento de $35,02 \%$. A média da receita no período analisado foi de $\mathrm{R} \$ 40,69$ milhões, que contempla as arrecadações municipais mais os valores recebidos por transferências oriundas da União.

Figura 2 - Receita líquida total, em milhões de reais, no período 2003-2011

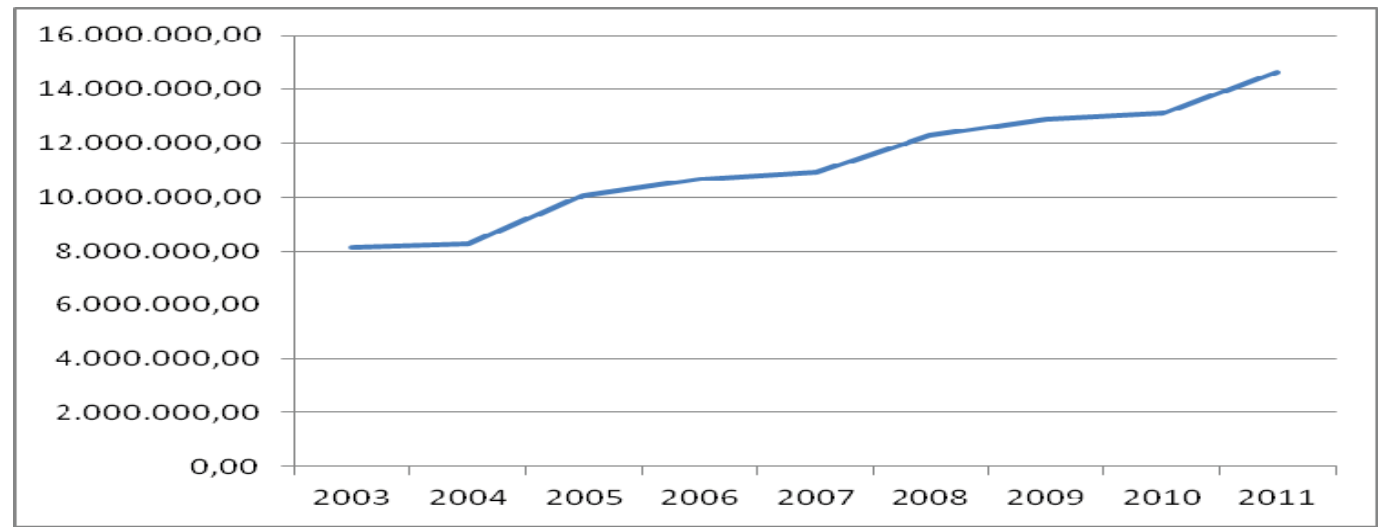

Fonte: Prefeitura Municipal de Marau (2012).

Na Figura 3, apresenta-se a comparação entre receita própria e receita total e transferências no período de 2003 a 2011. Observa-se que as transferências federais dividem-se em transferências constitucionais, cujo objetivo do repasse é amenizar as desigualdades e promover o equilíbrio socioeconômico entre os estados e municípios. 
Figura 3 - Comparação entre receita própria, transferências e receita total, de 2003 a 2011, em mil reais

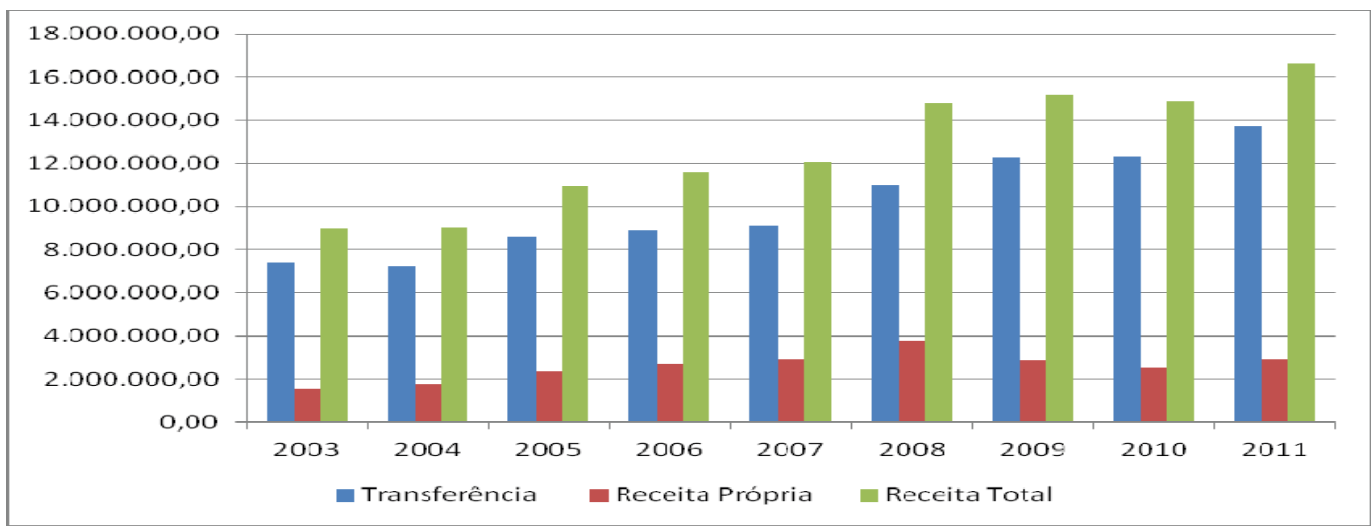

Fonte: Prefeitura Municipal de Marau (2012).

As principais transferências são os fundos de Participação do Estado e do Distrito Federal (FPE), de Participação dos Municípios (FPM), de Compensação pela Exportação de Produtos Industrializados (FPEX), de Manutenção e de Desenvolvimento do Ensino Fundamental e de Valorização do Magistério (Fundef), que representaram $\mathrm{R} \$ 4,32$ milhões de recursos no período 2003-2011, e o ITR.

Quanto às transferências legais, destacam-se o Programa Nacional de Alimentação Escolar (PNAE), que de 2003 a 2011 acumulou R\$ 832,62 milhões, o Programa Nacional de Apoio ao Transporte Escolar (PNATE), que representou de 2003 a 2009 R $\$ 289,91$ mil, o Programa Dinheiro Direto na Escola (PDDE), que de 2003 a 2011 representou $\mathrm{R} \$$ 7,96 mil. Quanto às transferências voluntárias, que são recursos repassados da União aos estados, ao Distrito Federal e aos municípios com a finalidade de realizar obras ou serviços de interesse comum, como o Sistema Único de Saúde (SUS), no mesmo período, representou $\mathrm{R} \$$ 8,16 milhões para Marau.

Com base no exposto, Marau depende muito das transferências de recursos para destinar aos seus gastos. Esse é um cenário muito comum em grande parte dos municípios tanto em nível estadual quanto em nível nacional, pois, a partir da CF/1988, os municípios passam a apresentar destinos mais direcionados de recursos, relevando uma propensão nas mudanças de preferências alocativas. O crescimento médio anual das transferências representa $7,06 \%$, as receitas próprias $7,39 \%$, e a receita total $7,12 \%$ de crescimento médio no período em análise.

Nesse sentido, verifica-se que, nos anos 2003 e 2004, as transferências estavam equiparadas à receita total, o que também ocorreu nos três anos seguintes (2005, 2006 e 2007). Nesse período, a receita total reduziu e ocorreu um aumento de transferências. Já, no ano 2008, ocorreu um aumento da receita própria, o que 
pode estar associado ao princípio de benefícios (RIANI, 2002), de que cada indivíduo na sociedade pagará um tributo de acordo com o montante de benefícios que ele recebe. Porém, em 2009, ocorreu uma redução na receita própria e alavancam-se as transferências, consequência da crise financeira internacional, que, mesmo não sendo um evento local, provocou redução no nível de renda da população e afetou o poder público no total de arrecadação própria.

A dinâmica das receitas marauenses são explicadas com base nos dados apresentados na Figura 4, que faz uma análise comparativa da participação da receita tributária com a receita total no período de 2003 a 2011.

Figura 4 - Participação da receita tributária em relação à receita total no período 2003-2011, em mil reais

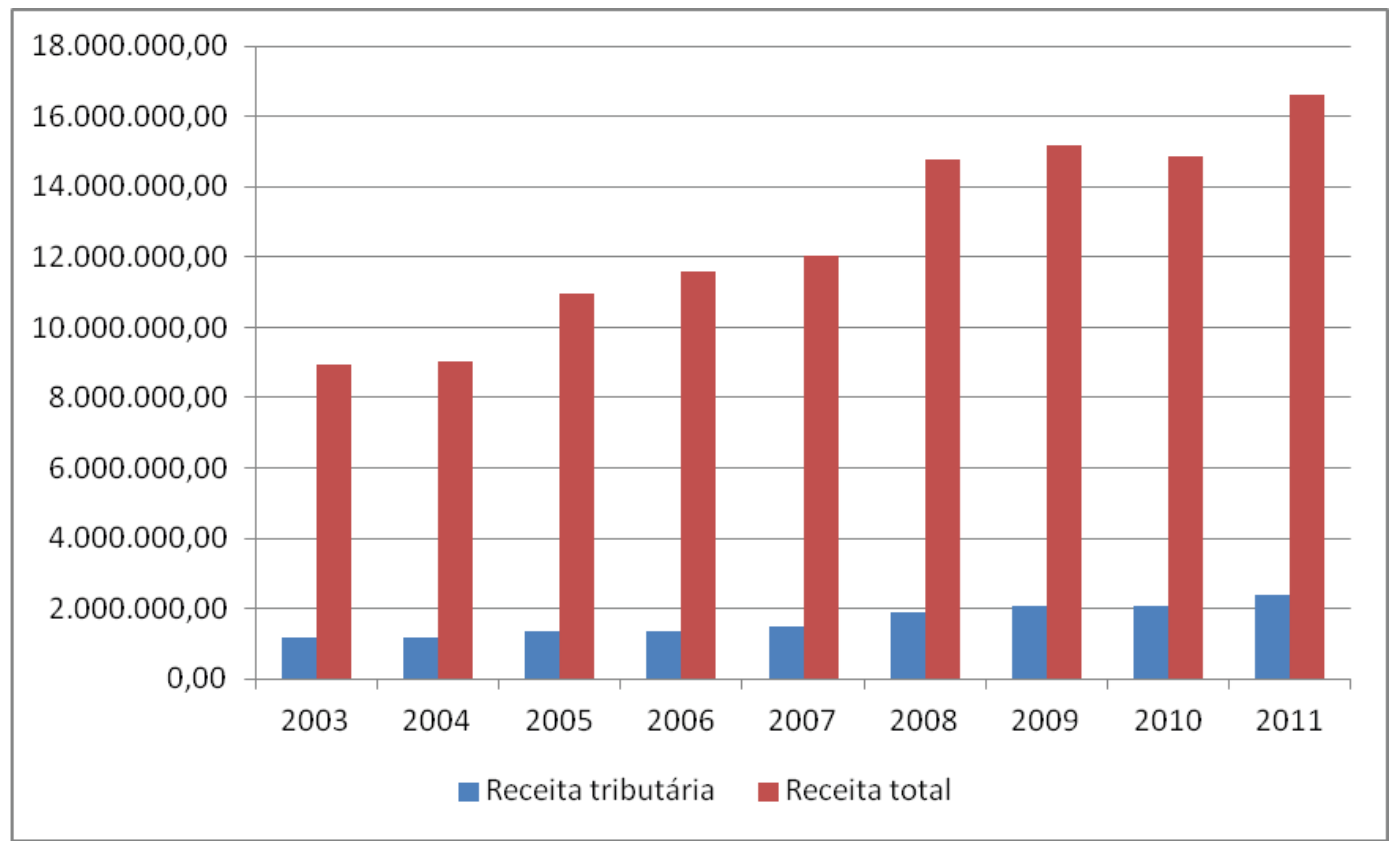

Fonte: Prefeitura Municipal de Marau (2012).

A receita tributária é composta pelo montante de impostos, taxas e contribuições de melhoria pago pelos contribuintes decorrente da renda de suas propriedades e outros benefícios diretos. Os impostos que mais se destacam são IPTU, ITBI e ISSQN, enquanto as taxas mais importantes são a taxa de limpeza pública, a de licença para funcionamento de estabelecimentos comerciais, industriais e de prestação de serviço (74,70\%), a taxa pelo exercício de poder de policiamento $(25,30 \%)$ e a contribuição de melhoria, bem como a contribuição para melhoria da 
pavimentação e obras complementares (100\%). A média de arrecadação de receita tributária no período analisado é de $\mathrm{R} \$ 5,54$ milhões, e representa um crescimento médio de $7,12 \%$.

A receita tributária contribui com $8,33 \%$ da receita total. $\mathrm{O}$ incremento de $30,46 \%$ das receitas deve-se ao aumento do número de prestadores de serviço e de residências construídas, em virtude do programa de beneficiamento habitacional do governo federal, de ruas pavimentadas, com a expansão do perímetro urbano. De fato, os recursos arrecadados levam o município a ter menor dependência das transferências para custear suas despesas.

Na Figura 5, apresentam-se as transferências federal e estadual, comparando-as ao volume de receita própria gerada, que é tudo o que o município arrecadou em termos de impostos e taxas no período 2003-2011.

Figura 5 - Participação das transferências federal e estadual em relação à receita própria no período 2003-2011, em mil reais

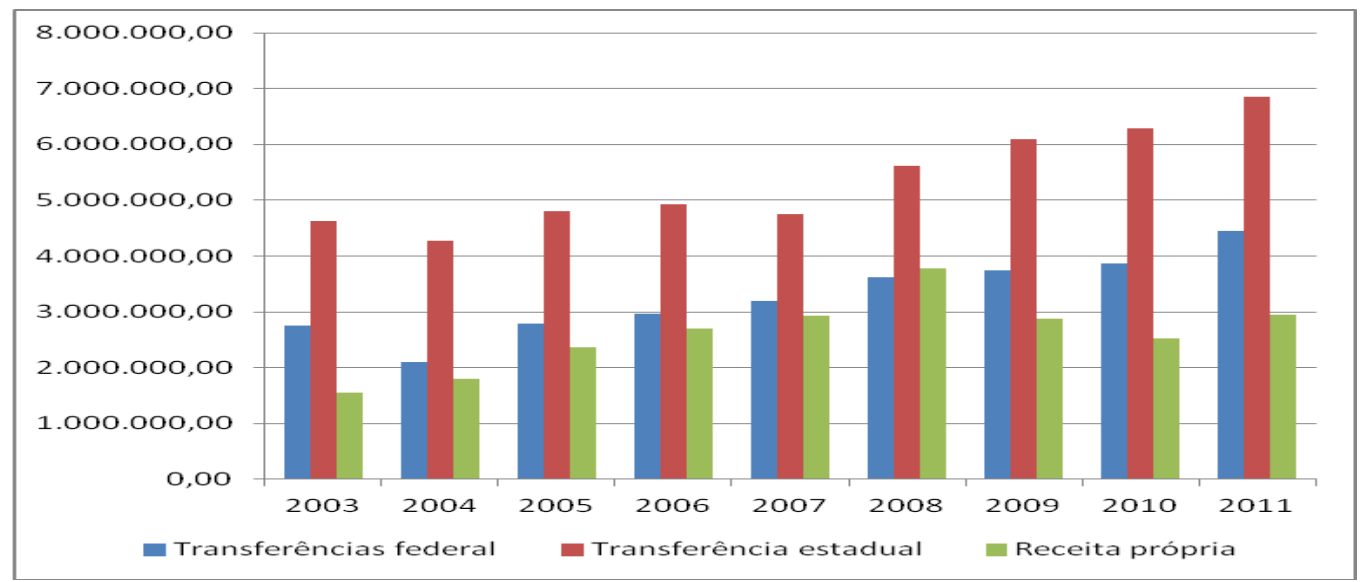

Fonte: Prefeitura Municipal de Marau (2012).

As transferências estaduais representam maior valor, pois a arrecadação de ICMS (principal imposto de transferência do Estado) IPVA e IPI, no montante, são valores superiores ao FPM (principal imposto de transferência da União), ao ITR, e à Lei Kandir. As transferências estaduais totalizaram $\mathrm{R} \$ 42,21$ milhões no período de 2003 a 2011, e as transferências federais $R \$ 29,46$ milhões, no mesmo período. As transferências federais representam um crescimento médio anual de 5,49\%, as transferências estaduais $4,46 \%$, e a receita própria dessa categoria representa $7,39 \%$. 
Na Figura 6, apresenta-se o volume de recursos arrecadados em impostos municipais no período 2003-2009. Os dados revelam que o valor do ISSQN cresceu, em média, $14,84 \%$, o ITBI 9,36\%, o IRPF $14,16 \%$, o IPTU $2,42 \%$, e outras taxas $0,94 \%$.

Figura 6 - Recursos arrecadados em impostos municipais, de 2003 a 2011, em mil reais

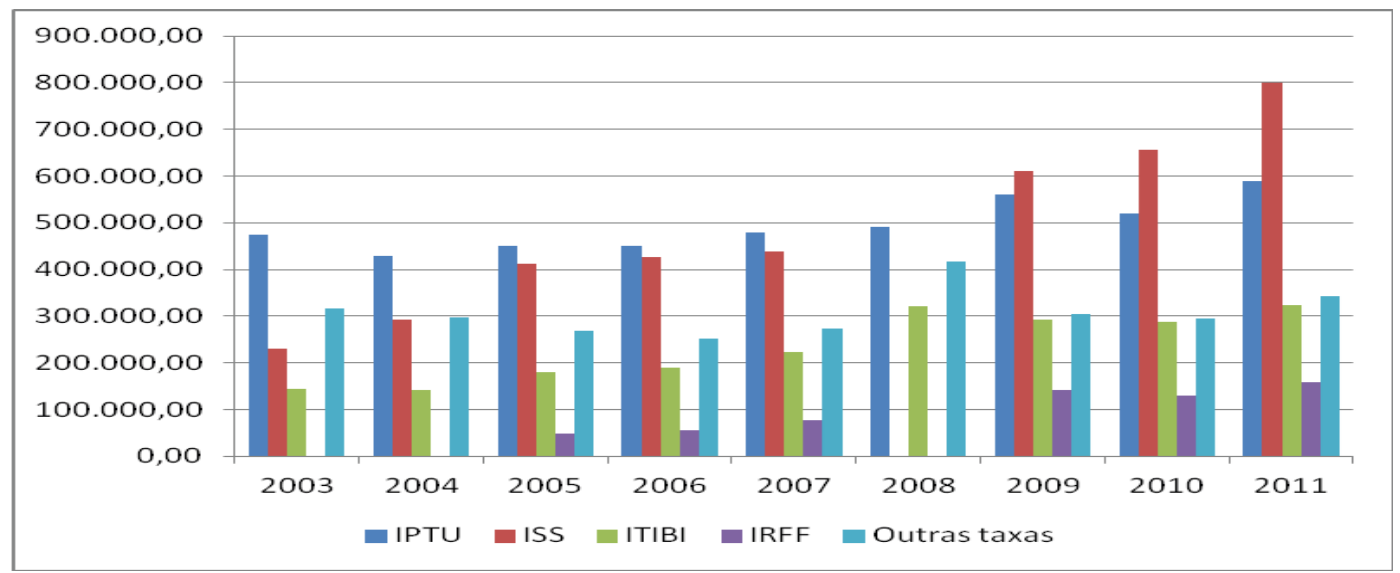

Fonte: Prefeitura Municipal de Marau (2012).

Quanto ao ITBI, manteve-se em alta no período de 2006 a 2008, teve reduzido seu valor arrecadado em 2009 , responsável por 18,13\% da participação do total das receitas próprias. O IPTU obteve um aumento significativo em 2003, pois o aumento da arrecadação do ITBI alavancou a arrecadação do IPTU, devido ao Programa Minha Casa, Minha Vida. O ITBI de 2008 foi responsável pelo aumento do valor do IPTU em 2009. Consolidando os três impostos, eles representam um total de R $\$$ 10,40 milhões, e as taxas correspondem a 18,13\% das receitas tributárias e uma arrecadação de R\$2,76 milhões no período em análise. As taxas e o ITBI crescem na mesma proporção, em 2008, o ITBI contribuiu mais em relação às taxas para 0 aumento da arrecadação tributária.

$\mathrm{Na}$ Figura 7, pode-se visualizar o volume de transferências dos impostos ICMS, IPVA e IPI no período transcorrido entre 2003 e 2009, que apresenta crescimento constante de transferências do ICMS. A CF/1988, estabelece que os estados devem transferir aos municípios 50\% do IPVA, 25\% do ICMS, 25\% do IPI. 
Figura 7 - Transferências de ICMS e IPVA no período 2003-2011, em mil reais

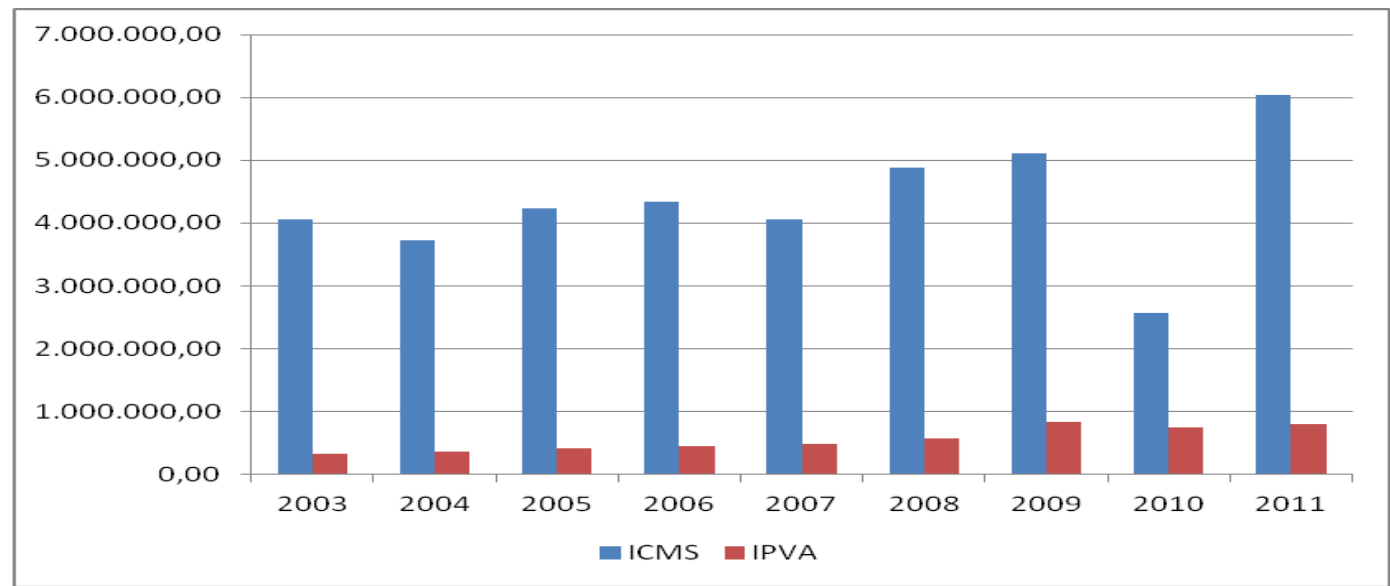

Fonte: Prefeitura Municipal de Marau (2012).

Consequência do polo industrial e do surgimento de empresas nos demais ramos, a arrecadação do ICMS em 2003 foi de R\$ 4,052 milhões. Em 2011, o imposto arrecadou $\mathrm{R} \$ 6,042$ milhões, representando um crescimento anual médio de 4,54\% ao ano. O IPVA, em 2003, arrecadou R\$ 324 mil e, em 2011, arrecadou R\$ 803 mil, um incremento médio anual de $10,60 \%$.

No período de 2008 a 2009, o cenário se modificou em função de medidas adotadas pelo governo federal. Assim, o ICMS, de 2007 para 2008, cresceu 21,37\% devido ao aumento do consumo da população, à redução do IPI para veículos e produtos da linha branca, ao programa habitacional Minha Casa, Minha Vida, que alavancou a construção civil e o comércio de materiais de construção. No período de 2008 a 2009, à medida que o ICMS aumentou, o IPI teve a mesma redução (21,37\%). O IPVA, com o incentivo governamental para aquisição de automóveis pela redução do IPI, cresceu 2,59\% em 2009, comparativamente ao ano anterior.

Na Figura 8, apresenta-se o volume de transferência do ITR e da LC n 87/1996 para o município de Marau, no período de 2003 a 2011. O valor de ITR transferido, em 2003, foi de $\mathrm{R} \$ 9,12$ milhões e, em 2011, de $\mathrm{R} \$ 12,76$ milhões, apresentando um crescimento médio anual de 3,69\%. Quanto à Lei Kandir, no ano de 2003, transferiu $\mathrm{R} \$ 108,83$ milhões e, em 2011, o valor foi de $\mathrm{R} \$ 208,48$ milhões. Isso representou um incremento médio anual de $7,49 \%$ no período analisado. 
Figura 8 - Volume de transferência de ITR e da LC n 87/1996 para Marau de 2003 a 2011, em mil reais

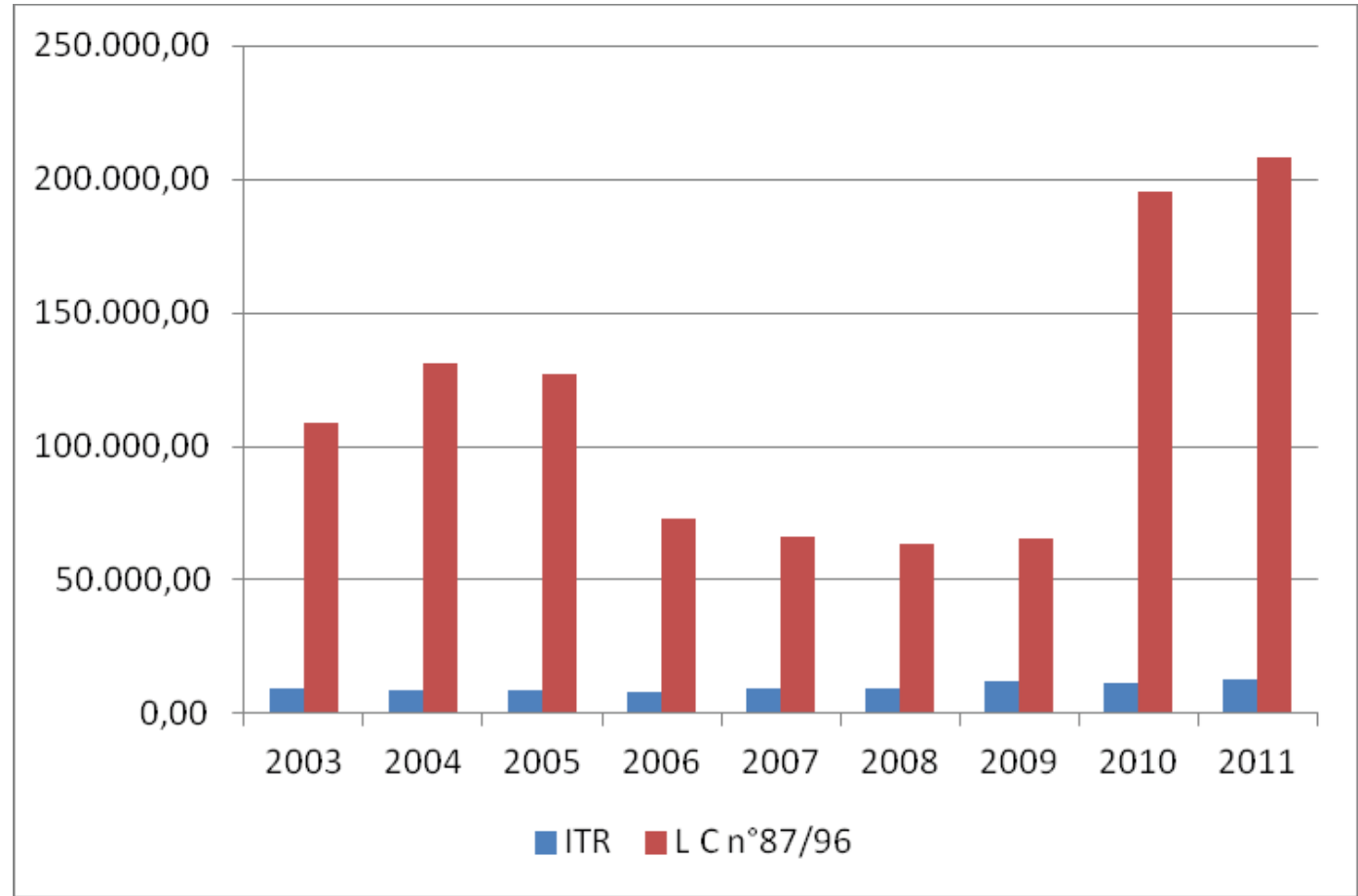

Fonte: Prefeitura Municipal de Marau (2012).

O Fundo de Participação dos Municípios, oriundo dos tributos da União (IR e IPI), comparado à receita total no período 2003-2011, é apresentado na Figura 9. O FPM é a principal transferência federal arrecadada por Marau. O crescimento médio anual do FPM foi de 8,54\% e o arrecadado no período em análise representa $19,46 \%$ em relação à receita total que acumulou $\mathrm{R} \$ 104,78$ milhões. 
Figura 9 - Fundo de Participação dos Municípios comparado à receita total do período 2003-2011, em mil reais

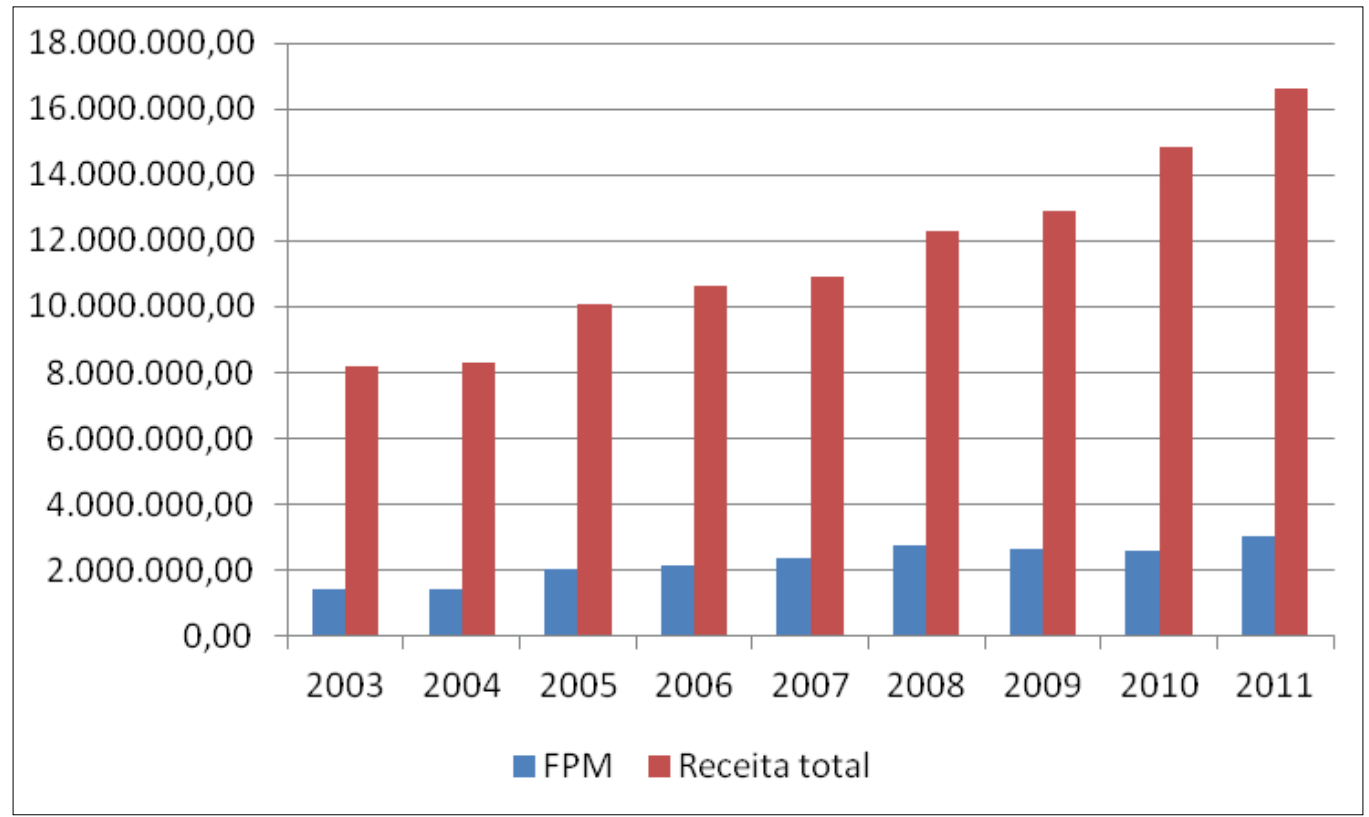

Fonte: Prefeitura Municipal de Marau (2012).

O volume de recebimentos a título de transferência do ICMS é apresentado na Figura 10. No período 2003-2011, o ICMS é a transferência estadual de maior peso arrecadado pelo município. O valor médio de cota-parte do ICMS é de R $\$ 161,19$ milhões e representa $39,61 \%$ de participação no total da receita total. Esse acréscimo pode ter sido decorrido da diminuição das receitas próprias do município. No período analisado, a cota-parte do ICMS de Marau é 36,60\% superior ao total da receita tributária do município. 
Figura 10 - Recebimento da transferência de ICMS em relação à receita total no período 20032011, em mil reais

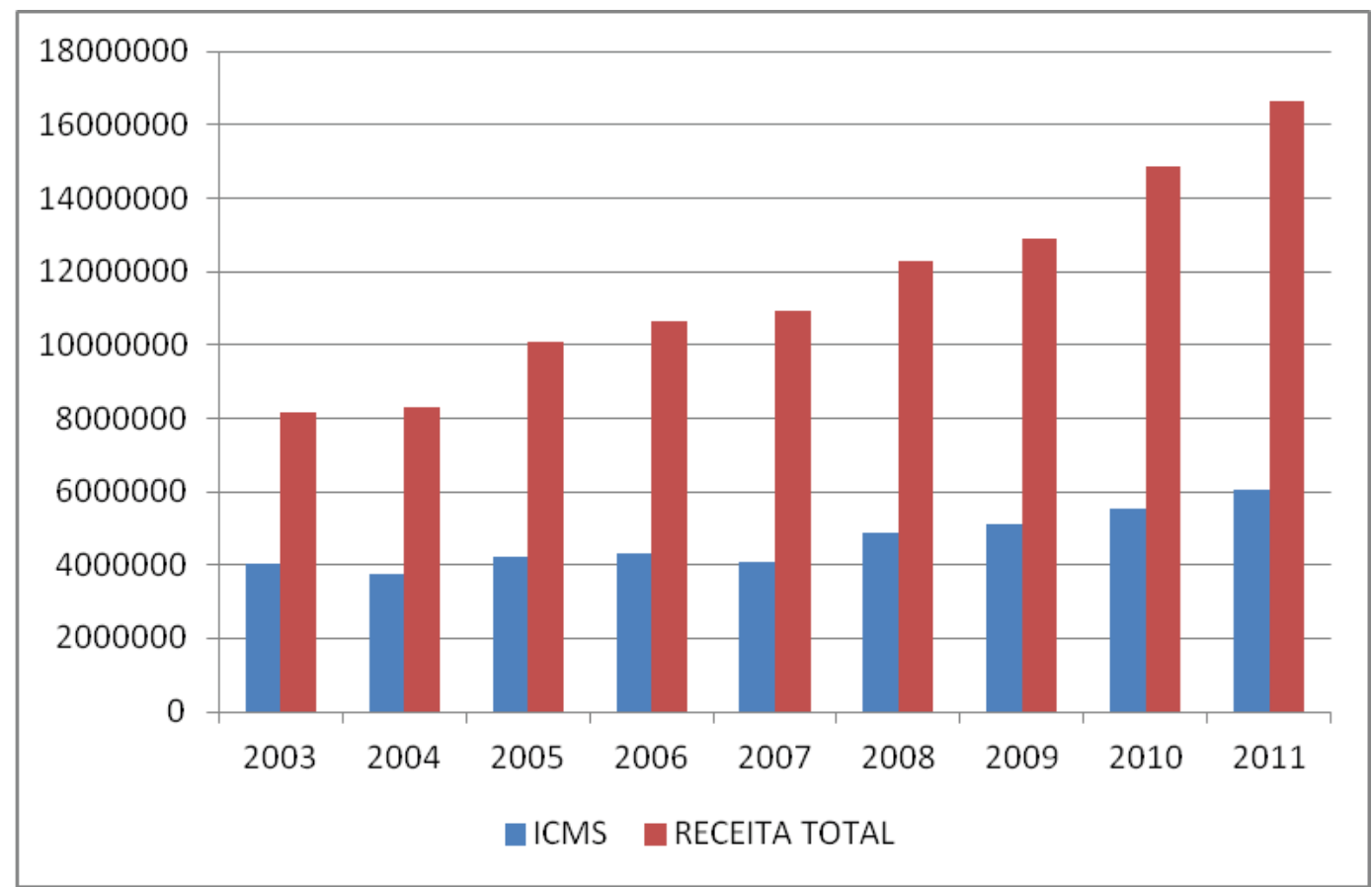

Fonte: Prefeitura Municipal de Marau (2012).

Cabe ressaltar que $25 \%$ do ICMS retornam para o município, e caso o município tenha empréstimo com o Estado, por exemplo, para aquisição de maquinário, material asfáltico, etc., a parcela de pagamento do empréstimo é descontada mensalmente do repasse do ICMS ao município (retenção de ICMS). O ICMS no mesmo período apresentou um crescimento médio de 4,54\%.

A média do volume de gastos em investimentos foi de $\mathrm{R} \$ 3,29$ milhões em 2003 e de $\mathrm{R} \$ 1,49$ milhão em 2011, uma redução média de 8,39\% no período em análise. 
Figura 11 - Volume de investimentos comparados à receita total no período 2003-2011, em mil reais

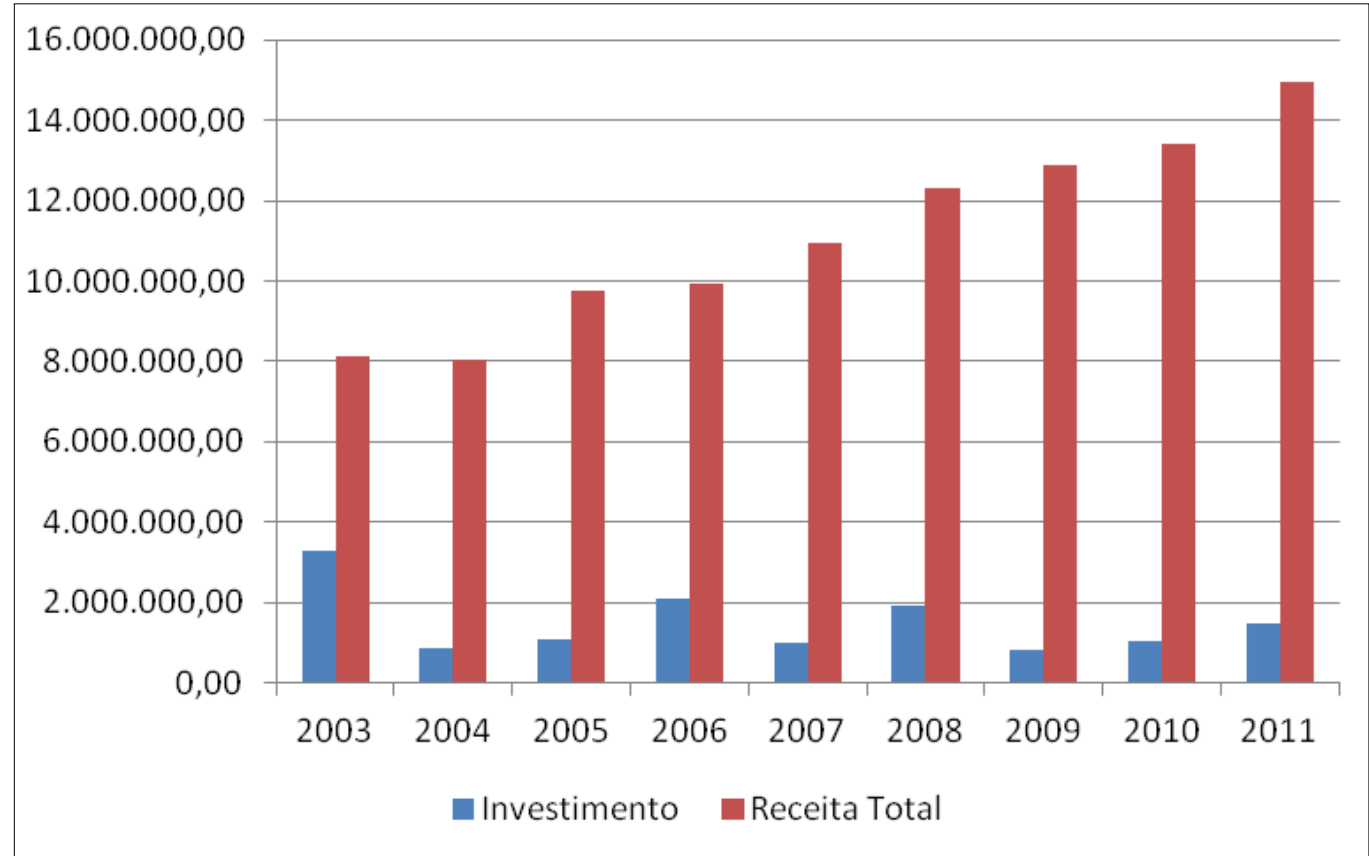

Fonte: Prefeitura Municipal de Marau (2012).

A Secretaria da Cidade e Trânsito é o setor que mais gera gastos em investimentos, devido à pavimentação de ruas e à manutenção de iluminação pública, embora melhorando a infraestrutura urbana e possibilitando o bem-estar e a qualidade de vida dos munícipes. O gasto em investimentos é seguido pelas secretarias da Educação e da Saúde.

A Secretaria da Educação promove o desenvolvimento social da população, com a ampliação das escolas de educação infantil e ensino fundamental, com a melhoria de infraestrutura, do material pedagógico, da informatização, e da merenda escolar. A Secretaria da Saúde, por sua vez, promove investimentos em programas de saúde da família, mantém convênio com hospital, plantão 24 horas e agentes comunitários de saúde para visitas aos domicílios. Os valores das despesas correntes e de capital podem ser conferidos na Figura 12. 
Figura 12 - Comparativo entre despesa corrente e despesa de capital no período 2003-2011, em mil reais

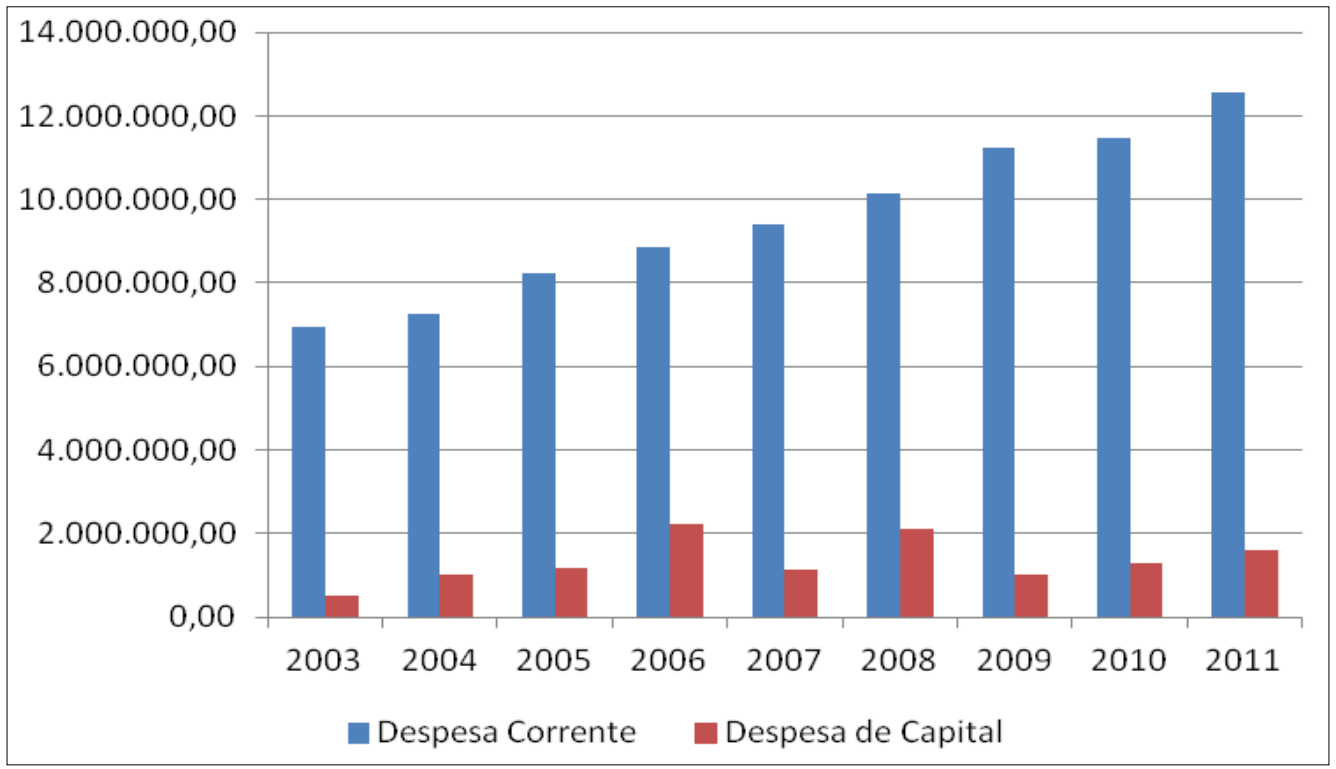

Fonte: Prefeitura Municipal de Marau (2012).

As despesas correntes em 2003 apresentam um volume de $\mathrm{R} \$ 6,95$ milhões e, em 2011, de R $\$ 12,54$ milhões, um crescimento anual médio de 6,78\%. As despesas de capital representaram $\mathrm{R} \$ 510,31$ mil, em 2003 , e $\mathrm{R} \$ 1,59$ milhão em 2011, apontando um crescimento médio anual de 13,49\%.

Para descrever como se comportam os gastos mínimo, social e econômico, utilizou-se a metodologia de Rezende (1997). O autor explica a relação gasto social > gasto mínimo > gasto econômico, a partir de 1988, por meio de uma acentuada contratação dos gastos de natureza econômica. Seguindo esta mesma lógica analítica, os dados relativos à Marau revelam que há uma alteração no padrão de preferências alocativas dos gastos públicos em função da descentralização dos recursos. Sendo assim, em Marau, observa-se mais gasto social comparativamente aos gastos mínimo e econômico.

Assim, os gastos realizados pela Prefeitura Municipal de Marau, conforme consta na Figura 13, revelam alocação de crescimento constante no período 20032011. Contudo, a partir de 2006, nota-se um aumento expansivo do gasto social. Em 2009 , esse gasto ultrapassou o gasto econômico em $1,22 \%$. Isso pode estar relacionado à tese apresentada por Klein (2010). As despesas correntes (despesas com pessoal e encargos sociais têm maior peso dentro da categoria) que em 2003 apresentavam $\mathrm{R} \$ 20,34$ milhões, em 2011 , foram de $\mathrm{R} \$ 29,67$ milhões, um aumento de $60 \%$. As despesas de capital, que envolvem os investimentos, em 2003 apresentavam $\mathrm{R} \$ 965$ mil e, em 2011, passaram a $\mathrm{R} \$ 6.99$ milhões, um incremento de 13,80\%. 
Figura 13 - Comparativo entre gasto social, gasto mínimo e gasto econômico, com o total de gastos no período de 2003 a 2011

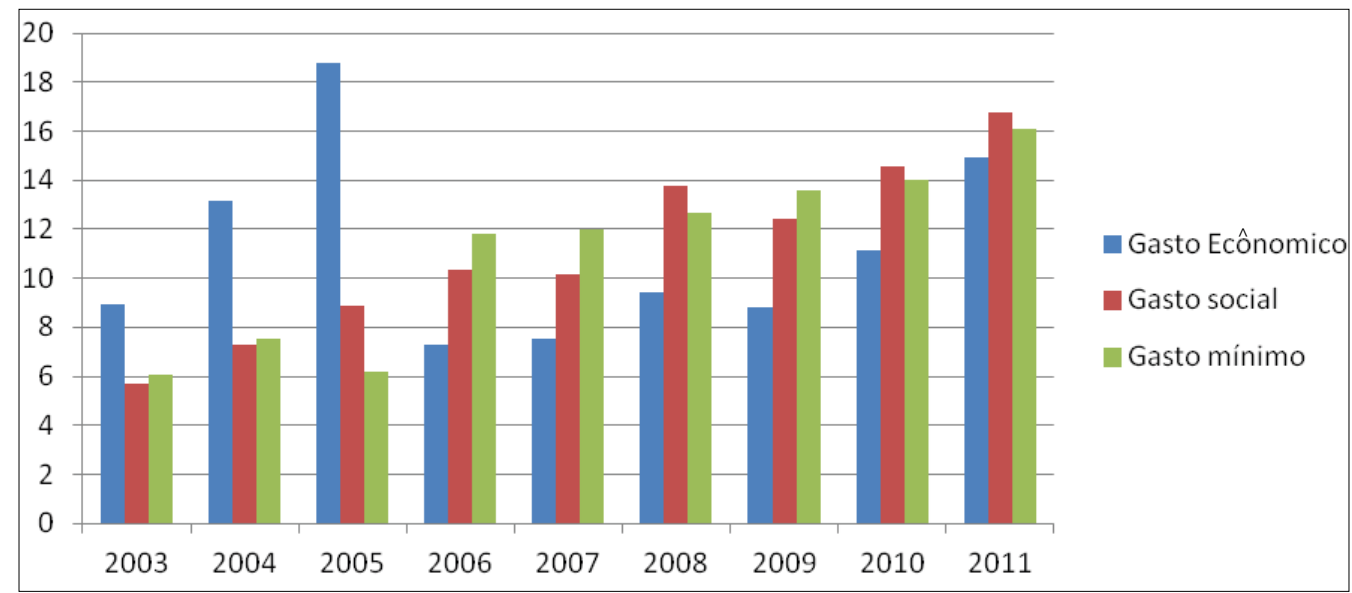

Fonte: Prefeitura Municipal de Marau (2012).

A função de administração e planejamento está diretamente ligada à "máquina pública", que envolve elevados gastos em relação às despesas totais. No entanto, tais gastos poderiam ser reduzidos para realizar investimentos ou aplicações em segurança e defesa, que representam baixos níveis de alocação, comparativamente à representatividade dessa questão para os marauenses.

Na Tabela 5, observam-se os gastos da Câmara de Vereadores (pagamentos aos vereadores, funcionários, despesas administrativas e diárias) e do Judiciário (gasto com assessoria jurídica), bem como o gasto médio por habitante, no período de 2003 a 2011.

Tabela 5 - Percentual médio de gastos e gasto médio por habitante no período 2003-2011

\begin{tabular}{c|c|c|c|c|c}
\hline \multirow{2}{*}{ Ano } & \multicolumn{2}{|c|}{ Percentual do gasto médio em relação ao total do gasto mínimo } & Gasto médio por \\
\cline { 2 - 5 } & Legislação & Judiciário & Administração & Defesa e segurança & habitante \\
\hline 2003 & 8,73 & 0,86 & 90,40 & & 184,01 \\
2004 & 9,12 & 0,80 & 90,05 & 0,02 & 229,64 \\
2005 & 12,31 & 1,06 & 82,73 & 3,88 & 187,16 \\
2006 & 6,44 & 0,54 & 90,50 & 2,50 & 359,63 \\
2007 & 6,52 & 0,54 & 90,06 & 2,85 & 363,70 \\
2008 & 6,49 & 0,54 & 89,07 & 3,82 & 385,72 \\
2009 & 6,77 & 0,54 & 89,23 & 3,44 & 412,96 \\
2010 & 6,68 & 0,52 & 88,55 & 4,23 & 425,81 \\
2011 & 6,18 & 0,53 & 89,37 & 3,90 & 489,19 \\
\hline
\end{tabular}

Fonte: Prefeitura Municipal de Marau (2012) 
Tabela 6 - Percentual médio de gasto social e gasto médio por habitante no período 2003-2011

\begin{tabular}{|c|c|c|c|c|c|c|}
\hline \multirow[b]{2}{*}{ Ano } & \multicolumn{5}{|c|}{ Percentual do gasto médio em relação ao gasto total social (GS) } & \multirow{2}{*}{$\begin{array}{l}\text { Gasto médio } \\
\text { por habitante }\end{array}$} \\
\hline & $\begin{array}{c}\text { Educação e } \\
\text { Cultura }\end{array}$ & $\begin{array}{c}\text { Saúde e } \\
\text { Saneamento }\end{array}$ & $\begin{array}{l}\text { Assistência e } \\
\text { Previdência }\end{array}$ & $\begin{array}{l}\text { Habitação e } \\
\text { Urbanismo }\end{array}$ & $\begin{array}{l}\text { Esporte e } \\
\text { lazer }\end{array}$ & \\
\hline 2003 & 58,40 & 29,85 & 1,83 & 8,78 & 1,13 & 398,40 \\
\hline 2004 & 54,56 & 32,56 & 2,17 & 8,72 & 1,98 & 510,88 \\
\hline 2005 & 52,16 & 30,09 & 4,02 & 8,47 & 5,25 & 619,71 \\
\hline 2006 & 47,05 & 28,17 & 2,93 & 19,72 & 2,12 & 724,49 \\
\hline 2007 & 48,96 & 32,15 & 1,94 & 14,13 & 2,80 & 708,49 \\
\hline 2008 & 44,99 & 30,91 & 1,47 & 20,36 & 2,25 & 961,20 \\
\hline 2009 & 50,53 & 34,94 & 1,54 & 11,65 & 1,32 & 869,50 \\
\hline 2010 & 51,34 & 34,02 & 1,22 & 11,53 & 1,88 & 1017,50 \\
\hline 2011 & 50,60 & 34,51 & 1,56 & 10,08 & 3,24 & 1170,66 \\
\hline
\end{tabular}

Fonte: Prefeitura Municipal de Marau (2012).

Nos gastos com saúde estão contemplados os serviços prestados no posto central de saúde: os atendimentos, os exames, as pequenas cirurgias, as feiras da saúde, as campanhas referentes aos vários temas (diabetes, Aids, hepatite C), o pagamento de palestrantes, o aluguel de auditório, as despesas com comunicação e mídia, o serviço de plantão médico disponível no Hospital Cristo Redentor, os materiais de expediente, a energia elétrica, a água, entre outras despesas. Os recursos do Programa Saúde da Família são destinados ao pagamento de doze postos de saúde em funcionamento, sendo que duas salas comerciais são alugadas, à manutenção, aos insumos, aos equipamentos, aos prontuários, às folhas, à energia elétrica, à água e ao telefone. O Programa Agente Comunitário da Saúde paga os colaboradores que atuam na zona urbana e zona rural. $\mathrm{O}$ município também atende à população em treze unidades instaladas em regiões estratégicas com o Estratégia da Saúde da família e com o Centro de Apoio Psicossocial, que oferece orientação e tratamento psicológico aos dependentes químicos.

A assistência farmacêutica recebe auxílio das três esferas, ou seja, da União, do Estado e do município. No valor de baixa procedência, é o município que mais investe nessa subfunção, comprando medicamentos da lista básica, determinados pela legislação, parte dos remédios especiais fica por conta do Estado, e os controlados por conta da União.

$\mathrm{Na}$ área educacional, a educação infantil está representada por onze escolas. O ensino fundamental é contemplado também com onze escolas, sendo quatro delas na zona rural e sete na zona urbana. Há ainda uma escola de educação para jovens e adultos, com 120 alunos e doze professores, considerada referência em 
nível nacional. No total, há trezentos professores alocados nas escolas. O município também dispõe de duas salas de recursos multifuncionais para atendimento educacional especializado, que ocorre em turno inverso e é oferecido aos 42 alunos especiais, com fonoaudiólogos e psicopedagogos que supervisionam as escolas e auxiliam em caso de dificuldades de aprendizagem.

$\mathrm{Na}$ assistência e previdência social, o município oferece o programa Bolsa Família que, via convênio com a União, repassa os valores às famílias carentes e de extrema carência. Esse programa oferece serviços socioassistenciais continuados e proteção social especial de média e alta complexidade, com grupos de atividades para orientação, apoio e assessoria de economia doméstica, entre outras atividades. Os serviços de média complexidade referem-se ao tratamento de pessoas que estão em conflito com a lei, em contraprestação de serviço comunitário; os serviços de alta complexidade, por meio de auxílio e acompanhamento, referem-se ao tratamento de idosos e adolescentes em condições de descuido.

A área de habitação e urbanismo aloca recursos públicos para a pavimentação de ruas, canalização de esgotos e instalação de rede de água, além de melhorias nos acessos ao centro da cidade e aos pontos turísticos. Na Tabela 8, apresenta-se o percentual médio de gasto econômico e de gasto médio por habitante no período de 2003 a 2011.

Tabela 8 - Percentual médio de gasto econômico e gasto médio por habitante (2003-2011)

\begin{tabular}{|c|c|c|c|c|c|c|c|}
\hline \multirow[b]{2}{*}{ Ano } & \multicolumn{6}{|c|}{ Percentual do gasto médio em relação ao gasto econômico (GE) } & \multirow{2}{*}{$\begin{array}{l}\text { Gasto médio } \\
\text { por habitante }\end{array}$} \\
\hline & Agricultura & Comunicação & Energias & $\begin{array}{c}\text { Indústria, } \\
\text { Comércio e Serviço }\end{array}$ & Trabalho & Transportes & \\
\hline 2003 & 23,73 & 3,01 & 0 & 11,75 & 12,95 & 48,54 & 72,34 \\
\hline 2004 & 15,35 & 2,01 & 0 & 7,04 & 18,14 & 57,44 & 106,4 \\
\hline 2005 & 33,76 & 0,25 & 0 & 5,28 & 12,30 & 48,39 & 152,47 \\
\hline 2006 & 34,60 & 2,79 & 0,19 & 13,92 & 48,48 & - & 59,00 \\
\hline 2007 & 28,74 & 2,04 & 0,36 & 23,14 & 45,69 & - & 61,10 \\
\hline 2008 & 27,90 & 1,23 & 0,16 & 16,98 & 53,71 & - & 76,24 \\
\hline 2009 & 19,85 & 0,02 & 0,23 & 22,32 & 57,55 & - & 71,57 \\
\hline 2010 & 24,79 & 0 & 0,25 & 21,26 & 53,68 & - & 90,21 \\
\hline 2011 & 19,82 & 0 & & 35,09 & 44,99 & - & 121,19 \\
\hline
\end{tabular}

Fonte: Prefeitura Municipal de Marau (2012).

O governo municipal apoia o fortalecimento da pequena e média propriedade com auxílio à terraplanagem (até 80 horas de serviço), com brita (um metro a cada $12 \mathrm{~m}^{2}$ construídos), quatro horas de maquinários agrícolas para pequenos 
serviços (silos, colocação de tubos, pocilgas), promoção da pecuária (Lei Municipal $\mathrm{n}^{\mathrm{o}}$ 1.687/1992), locação de equipamentos agrícolas para produtores (espalhador de calcário, conchas hidráulicas, espalhador líquido, grampo para pedras, plaina hidráulica, segadeira, colhedora de canola), subsídio para aquisição de sementes de milho e de máquinas e equipamentos (programa Prodesa). Porém, com a redução da população na zona rural diminuiu também os gastos anteriormente descritos e aumentou os gastos na zona urbana, como proteção e benefícios ao trabalhador.

Quanto às atividades produtivas da indústria, do comércio e de serviços, Marau conta com 21 empresas instaladas e 24 em processo de instalação no distrito industrial, localizado na RS 324, Km 84. Para tanto, o governo municipal incentivou investidores com doação de lotes e instalação de infraestrutura básica (telefonia, água, luz e saneamento), também firmou parceria com a Faculdade Brasiliense de Educação para produção científica e de auxílio na resolução de problemas que os empresários enfrentam, como na elaboração de planos de negócios. O município também oferece salas comerciais para novos empreendedores, subsidiando o aluguel do espaço comercial em um período máximo de dois anos. O turismo ganha força a partir do ano de 2008, com a criação da Rota das Salamarias.

Os serviços de transporte, até o ano de 2005, eram ligados ao departamento de calçamento e urbanização do município. Entretanto, estudos e melhorias transferiram os transportes para o setor de habitação e urbanismo, dentro dos gastos sociais, o que representa o aumento do gasto social e a redução do gasto econômico.

\subsection{Análise dos dados}

Os dados de Marau revelam que o município recebe mais recebe verbas em transferências estaduais, sendo que desses valores, o mínimo estabelecido em legislação, $15 \%$ é investido em educação, $25 \%$ investido em saúde e o restante é destinado como recurso livre. Quanto à arrecadação, o IPTU e o ISSQN são as maiores fontes de receita, os impostos estaduais (ICMS) têm valores elevados e o IPVA manteve-se em constate elevação. A receita total aumentou 35,02\% no período analisado e o total de investimentos alavancou 13,80\% no período de 2003-2011.

Pelo método de análise da estatística simples, constatou-se que a soma do gasto total do município de Marau representou $\mathrm{R} \$ 373,245$ milhões e o gasto econômico participou com 7,37\% no gasto total; o gasto social atingiu $64,53 \%$ do total, e o gasto mínimo apresentou $28,08 \%$ do total. Quanto ao gasto mínimo, no período analisado (2003-2011), percebe-se que o governo municipal ocupa 90\% das despesas. Os dados sugerem ação pública urgente para redução do quadro funcional e realocação desses gastos em investimentos, que resultarão em retorno ao município.

Teoria e Evidência Econômica - Ano 21, n. 44, p. 186-220, jan./jun. 2015 
Referente aos gastos sociais, educação e cultura envolvem em média mais de $50 \%$ dos gastos, o que reflete em condições sociais e de desenvolvimento humano, por meio de investimentos e ações destinadas à ampliação e reforma, informatização de escolas, creches e centro de atendimento a crianças especiais.

$\mathrm{Na}$ área da saúde, mesmo com o desenvolvimento de ações voltadas às necessidades dos munícipes, existem lacunas e há necessidades da população que ainda não são supridas, o que leva a rever certos investimentos. Quanto ao saneamento, houve a instalação de rede de esgoto e de fossas sépticas, seguindo os princípios da sustentabilidade como técnica de gestão do município.

Os investimentos na área social promovem melhoria nos hábitos e nas condições de sobrevivência humana, em especial pelas práticas da equipe de assistência social. Habitação e urbanismo correspondem a organizar a cidade, com ruas trafegáveis e melhorias nos pontos turísticos do município.

Nos gastos econômicos, a agricultura sofreu alterações em todos os anos do período analisado. Até 2008, a atenção ao meio ambiente era competência da Secretaria da Agricultura, após, esse iten foi isolado, criando-se uma função específica para o mesmo, que de certa forma, a viação rural era isolada da agricultura e, depois de 2004, uniu-se para poder otimizar processos a uma mesma função. Os setores de indústria, comércio, serviços e trabalho, destacam-se por meio do crescimento dos gastos médios em virtude do alto nível de investimento por parte do poder público para a instalação de empresas e do alto comprometimento com a saúde do trabalhador por parte das empresas.

\section{Considerações finais}

Devido à complexidade, não se explica o comportamento dos gastos públicos por meio de um único fator, pois os gastos públicos são compostos por vários fatores, que os afetam direta ou indiretamente, bem como as mudanças que neles ocorrem.

A maioria dos recursos municipais é proveniente de transferências (ICMS, em especial), o que é característico em municípios de pequeno porte. Porém, foi possível identificar um incremento na receita própria nos últimos anos (IPTU e ISSQN, principalmente), salvo no ano de 2009, em que houve reflexo da turbulência global ocorrida em 2008.

Para a apresentação dos gastos no município em estudo, procede-se da seguinte maneira: gasto social > gasto mínimo > gasto econômico, confirmando a teoria apresentada por Rezende (1997). O aumento dos gastos sociais representa ações do governo que visam promover a sociedade por meio do investimento social em termos de educação e cultura, saúde e saneamento, assistência e previdência e 
habitação e urbanismo, o aumento desses gastos ocorre quando não há iniciativa por parte do setor privado, necessitando da interferência do governo para dividir os recursos para alocar nas funções de mais urgência em relação à sociedade. Os gastos sociais são os que mais apresentam retorno produtivo para o setor público, originados pela qualificação de mão de obra, condições de moradia, condições de saúde, que são fundamentais para a vida humana.

$\mathrm{Na}$ alocação de gastos públicos, há uma grande concentração de recursos para atividades burocráticas, o que encarece outras áreas importantes na administração pública municipal, entre as quais se destaca a saúde pública. Em relação aos gastos econômicos, as grandes corporações multinacionais são responsáveis por mais de $50 \%$ da geração de emprego municipal, os retornos fiscais das empresas são alocados no incentivo às novas micro e pequenas empresas do setor informal, que tem função secundária na geração de emprego e na movimentação da economia do município.

O município de Marau realiza investimentos públicos para evitar que a política fiscal impeça o crescimento da economia, o que contribui para o aumento da produtividade nos investimentos privados. Esse comportamento está associado ao efeito crowding-in (complementariedade), um componente da demanda agregada que induz o investimento privado por meio do incremento da demanda por bens e serviços desse setor e o aumento da disponibilidade de recursos originados aos efeitos positivos sobre o produto e a poupança agregada.

A alocação dos gastos públicos constitui uma função pública de destinação de recursos na execução de programas e ações com vistas à coletividade ou a um grupo específico de cidadãos. Riani (2002) afirma que todos os projetos de investimentos governamentais, sejam eles econômicos, técnicos, administrativos, financeiros ou sociais, precisam ser bem planejados e implementados em um contexto de políticas públicas que propiciem incentivos a um bom desempenho econômico e social.

Os resultados indicam que a alocação de gastos públicos em Marau, na categoria gasto mínimo, está concentrada em uma só função. $\mathrm{O}$ gasto econômico cresce à medida que a economia do município cresce e vice-versa. Ao analisar os gastos sociais, percebe-se forte alocação de recursos em educação e cultura, responsáveis pela elevação do padrão cultural e da dignidade humana, o que contribui para que o município seja um formador de opinião crítica e por apresentar padrão de qualidade de vida diferenciado. Portanto, o processo de tomada de decisão gerencial em nível de administração pública municipal, tendo Marau como espaço de investigação, deve ser orientado pela natureza dos gastos públicos, com menos alocação de recursos em atividades burocráticas e mais alocação de recursos na execução de programas e ações com vistas à coletividade, dentre os quais, aqueles que elevam o padrão da cultura e da dignidade humana. 


\title{
Allocation of public spending in Marau city: a critical reflection on the process of managerial decision making and economic development
}

\begin{abstract}
The purpose of this article is to discuss the theoretical foundations that guide the process of managerial decision-making at the level of municipal public administration. Therefore, it is necessary to analyze the nature of municipal spending and identify the one that contributed positively to the development site. Fiscal decentralization and the federal pact printed in federal Constitution of 1988 were the pillars of Brazil's democratization in the 1990s, but the public finances are a management problem for the consolidation of macroeconomic stability and the resumption of investment in most municipalities. The methodological procedures adopted to conduct the empirical study was the "case study" with quantitative data collected in Marau (RS), the city that ranks first in the index of the Federation of Industries of Rio de Janeiro (Firjam) of Development Municipal. The results indicate an increase in net income, investment and current expenditure, a reduction in capital expenditure in the review period. The composition of spending in the municipality of Marau is presented as follows: social expenditure $>$ minimum spending $>$ economic spending.
\end{abstract}

Keywords: Nature of public spending. Public Policy. Local public spending. Economic Development.

\section{Asignación del gasto público en Marau condado: una reflexión crítica sobre el proceso de toma de decisiones gerenciales y el desarrollo económico}

\section{Resumen}

El propósito de este artículo es discutir los fundamentos teóricos que guían el proceso de toma de decisiones de gestión en el nivel de gobierno municipal. Por lo tanto, es necesario analizar la naturaleza del gasto público municipal e identificar la que contribuyó positivamente al desarrollo local. La descentralización fiscal y el pacto federal impreso en CF / 88 fueron los pilares de la democratización de Brasil en la década de 1990, pero las finanzas públicas son un problema de gestión para la consolidación de la estabilidad macroeconómica y la reanudación de las inversiones en la mayoría de municipios. Los procedimientos metodológicos utilizados para llevar a cabo el estudio empírico fue el "estudio de caso", con un análisis cuantitativo de los datos recogidos en Marau (RS), del municipio que ocupa la primera posición en el índice de Río de Janeiro Federación de Industrias (Firjam) Desarrollo Municipal. Los resultados indican un aumento en los ingresos netos, la inversión y el gasto corriente, una reducción en los gastos de capital en el período. La composición del gasto en el municipio de Marau se presenta de la siguiente manera: gasto social>gasto mínimo>gasto económico.

Palabras clave: Naturaleza del gasto público. La política pública. Gasto público local. Desarrollo económico. 


\section{Notas}

1 Não se pode negar, contudo, a contribuição da Crítica de Lucas (1976) para microfundamentar os modelos macroeconômicos, mas o problema continuou essencialmente macroeconômico.

2 O paradigma Arrow-Debreu é o movimento que se originou a partir da busca de uma demonstração matemática da existência, unicidade e otimalidade do equilíbrio geral, justificando assim que o livre mercado seria a melhor forma que a economia encontraria para a alocação eficiente dos seus recursos (ARROW; DEBREU, 1954).

3 A situação ótima é equivalente ao Ótimo de Paretto.

4 Segundo Kohoma (2000), o imposto sobre transmissão intervivos de bens imóveis e de direitos reais sobre imóveis (ITBI) é um tributo municipal, incidente sobre a transmissão a qualquer título, por ato oneroso, de bens imóveis e de direitos reais sobre eles, exceto os de garantia, bem como sobre a cessão de direito.

5 Lei Complementar no 87/1996.

\section{Referências}

ACEMOGLU, D.; JOHNSON, S.; ROBINSON, J. A. Reversal of fortune: geography and institutions in the making of the modern world income distribution. The Quarterly Journal of Economics, Oxford, v. 117, n. 4, p. 1231-1294, Nov. 2002.

. The colonial origins of comparative development: an empirical investigation. American Economic Review, Nashville, v. 91, n. 5, p. 1369-1401, Dec. 2001.

AFONSO, J. R. et al. Municípios, arrecadação e administração tributária: quebrando tabus. Revista do BNDES, Rio de Janeiro, n. 10, p. 3-36, dez. 1998.

ARROW, K. J.; DEBREU, G. Existence of an equilibrium for a competitive economy. Econometri$c a$, New York, v. 22, n. 3, p. 265-290, July 1954.

BRASIL. Constituição da República Federativa do Brasil de 1988. Disponível em: <http://www. planalto.gov.br/ccivil_03/constituicao/constituicaocompilado.htm>. Acesso em: 15 ago. 2013.

BOWLES, S. Microeconomics: behavior, institutions, and evolution. New Jersey: Princeton University, 2006.

COELHO, A. L. C. A "velha” geografia econômica da nova geografia econômica: Lösch frente aos demais antecedentes da modelagem. Revista de Desenvolvimento Econômico, Salvador, v. 15, n. 27 , p. $67-74$, jun. 2013.

FARAH, M. F. S. Disseminação de inovações e políticas públicas e espaço local. Organização \& Sociedade, Salvador, v. 15, n. 45, p. 107-126, abr./jun. 2008.

FISCHER, S.; DORNBUSCH, R. Macroeconomia. 5. ed. São Paulo: Pearson Education do Brasil, 1991.

FEE. FUNDAÇÃO DE ECONOMIA E ESTATÍSTICA. Núcleo de Contabilidade Social. Dados do município de Marau, 2013. Disponível em: <http://www.fee.tche.br/sitefee/pt/content/estatisticas/pg_pib_municipal_sh.php>. Acesso em: 13 jul. 2013.

FOLEY, D. K.; MICHL, T. R. Growth and distribution. Cambridge: Harvard University, 1999. Capítulo 1, Introduction.

GADELHA, S. R. B.; DIVINO, J. A. Dominância fiscal ou dominância monetária no Brasil? Uma análise de causalidade. Economia Aplicada, Ribeirão Preto, v. 12, n. 4, p. 659-675, Dec. 2008. 
IPEA. INSTITUTO DE PESQUISA EM ECONOMIA APLICADA.. Banco de dados - Ipeadata. Disponível em: <www.ipeadata.gov.br>. Acesso em: 13 mar. 2013.

KLEIN, F. A. Reelection incentives and political budget cycle: evidence from Brazil. Revista de Administração Pública, Rio de Janeiro, v. 44, n. 2, p. 283-337, 2010.

MAS-COLELL, A.; WHINSTON, M. D; GREEN, J. R. Microeconomic theory. Oxford: Oxford University, 1995.

MOURA NETO, J. S.; PALOMBO, P. E. M. Lei de responsabilidade fiscal, transferências e a arrecadação própria dos municípios brasileiros. In: ENANPAD, 30, 2006. Anais... Salvador: Anpad, 2006. CD-ROM.

MUSGRAVE, R. A.; MUSGRAVE, P. B. Finanças públicas: teoria e prática. São Paulo: Campus, 1980.

NEDUZIAK, L. C. R. Uma comparação do baixo crescimento econômico brasileiro em relação aos países do BRICS. Conjuntura Global, Curitiba, v. 2, n. 4, p. 201-204, out./dez. 2013.

NORTH, D. Institutions, institutional change and economic performance. Cambridge: Cambridge University Press, 1990.

OATES, W. E. Federalismo fiscal. Madrid: Instituto de Estudios de Administración Local, 1977. POHLMANN, M. C.; IUDÍCIBUS, S. Tributação e política tributária: uma abordagem interdisciplinar. São Paulo: Atlas, 2006.

PORTAL BRASIL. Governo adota pacote de estímulo à economia. 01 dez. 2011. Disponível em: <http://www.brasil.gov.br/governo/2011/12/governo-adota-pacote-de-estimulo-a-economia>. Acesso em: 27 ago. 2014.

PREFEITURA MUNICIPAL DE MARAU. Relatórios Contábeis 2003-2011. Marau: Prefeitura Municipal de Marau, 2012.

RAIS. RELAÇÃO ANUAL DE INFORMAÇÕES SOCIAIS. Dados da RAIS do município de Marau, 2010. Disponível em: <http://www.rais.gov.br/sitio/index.jsf>. Acesso em: 15 ago. 2013.

REZENDE, F. C. Descentralização, gastos públicos e preferências alocativas dos governos locais no Brasil (1980-1984). Dados, Rio de Janeiro, v. 40, n. 3, 1997.

RIANI, F. Economia do setor público: uma abordagem introdutória. 4. ed. São Paulo: Atlas, 2002.

SAMUELSON, P. Diagrammatic exposition of a theory of public expenditure. The Review of Economics and Statistics, Cambridge, v. 37, n. 4, p. 350-356, 1955.

SCHUMPETER, J. A teoria do desenvolvimento econômico. São Paulo: Abril Cultural, 1982. Coleção Os economistas.

SIEDENBERG, D. R. Dicionário do desenvolvimento regional. Santa Cruz: Edunisc, 2006.

TESOURO NACIONAL. Transferências voluntárias da união aos municípios: valores originais R\$ mil 1997-2010. Disponível em: <ttp://www.tesouro.fazenda.gov.br/>. Acesso em: 20 mar. 2013.

TIEBOUT, C. A pure theory of local expenditures. Journal of Political Economy, Chicago, v. 5, n. 64, p. $416-424,1956$.

VASCONCELOS, M. A. S.; GARCIA, M. E. Fundamentos de economia. 3. ed. São Paulo: Saraiva, 2008. 